\title{
CHROMOSOME DISTRIBUTION AND SPONTANEOUS CHROMOSOME BREAKAGE IN TRILLIUM GRANDIFLORUM
}

\author{
ALFRED RUTISHAUSER \\ Institut für allgemeine Botanik Universität Zürich
}

I. INTRODUCTION

Received 3.iii. 56

IN I940 Darlington and La Cour showed that the metaphase chromosomes of $T$. grandiflorum and other Trillum species are composed of more and less strongly stained segments when they are exposed before fixation to a temperature near freezing point. The regions weakly stained with leuco-basic fuchsin were named " differential segments". They correspond to the deeply stained chromocentres of resting nuclei, as Kurabayashi (1952a) was also able to show, and, therefore, they are identical to the heterochromatin of other organisms. Resende (1945) would prefer the name olisterochromatin for this chromatin type. In this paper, following a suggestion of Prof. Darlington, we use the abbreviation $\mathrm{H}$-segments for heterochromatic segments.

Position and number of $\mathrm{H}$-segments was constant within an individual in the experiments of Darlington and $\mathrm{La}$ Cour, but differences appeared when corresponding chromosomes of different test plants were compared with one another. Surprisingly, the partners of homologous chromosome pairs of the same plants often proved to be heteromorphic in so far as they could show variation in number and position of H-segments. Darlington and La Cour speak in such case of a hybrid chromosome complement.

The present work was originally undertaken with the intention of examining the question of the constancy of $\mathrm{H}$-segments by crossbreeding experiments. These experiments were made possible by the fact that instead of $F_{1}$-plants the endosperms of seeds of crosspollinated flowers were cytologically analysed. The method used was first applied to endosperms of lilies and Ranunculi (Rutishauser and Hunziker, I950 ; Rutishauser, I953).

In the course of investigations with species of the Trillium genus it was shown that the cytological analysis of the endosperm does not only give information about the constancy and behaviour of the heterochromatin in the crossbreeding experiments. It enables us further to follow the cytological consequences of " crossing-over" (Rutishauser, I955a,b) and especially the phenomenon of spontaneous chromosome breakage more easily than was formerly possible. Some first results concerning the latter problem have already been published by Brock (1954, 1955). 


\section{MATERIALS AND METHODS}

The samples were taken from three nurseries, C. Frikart Söhne, Stäfa/Zürich ; A. Vogt, Erlenbach/Zürich; B. Ruys AG., Dedemsvaart, Holland. The samples from Switzerland were designated $G_{1}, G_{2}$ and the samples from Ruys, Holland, $G H$.

As I was concerned with obtaining a complete "starvation effect" in the chromosomes, experiments were first made with duration and temperature of the cold-treatment. A deep freezing chest of Therma AG., Schwanden, with a thermostat of Sauter AG., Basle, was used as a refrigerator. The tolerance of this freezing chest was $\pm 0.2^{\circ} \mathrm{C}$. Temperatures of $0.3^{\circ}$ to $1.0^{\circ} \mathrm{C}$. with a duration of 4 days proved optimal. In some cases plants were successfully kept in a temperature of $1 \cdot 3^{\circ} \mathrm{C}$. for 5 days. Lower temperatures are unfavourable, because the chromosomes of the endosperm mitoses then become stickier, thereby making the investigation more difficult.

As a fixative for the roots, $2 \mathrm{BD}$ (La Cour, 1954) was used and for the endosperms either Carnoy or acetic alcohol. The description of the endosperm squash methods has already been given elsewhere (Rutishauser, 1956 and La Cour, 1954). Almost all endosperms were given the Feulgen treatment and post-stained with Orcein.

The staining capacity of the endosperm chromosomes decreases with the age of the seeds, but older endosperms were as a rule used in these investigations (fixation took place 5-6 weeks after pollination). The reason lies in the following peculiarities of endosperm development; the mitoses in young endosperms are mostly completely synchronised, and, therefore, the number of endosperms with divisions is small. Later, after the formation of the cell wall, which takes place about 5 weeks after pollination, the mitoses are scattered throughout the whole tissue as in the root-tips. And so in favourable cases one can assume that each endosperm contains analysable mitoses, which is of great importance especially for genetic investigations.

The photographs were taken with a Zeiss Miflex camera and the drawings made with a Zeiss-Winkel camera Lucida.

\section{CHROMOSOME COMPLEMENT OF PARENT PLANTS}

In all 70 plants were investigated and number, position and length of heterochromatic and euchromatic regions in each metaphase chromosome ascertained, and in this way the chromosome complement of the test plants was collated. All investigations were carried out on mitoses of the root-tips. This process and the prolonged coldtreatment has a certain inherent disadvantage : the chromosomes are easily shortened and particularly the $\mathrm{H}$-segments are less drawn out than in the preparations of Kurabayashi (1952b) and Haga and Kurabayashi (1954). But as the cytology of the endosperms of the same plant had to be investigated at the same time, it was not possible to use the ovules which were clearly more suitable for such experiments or to shorten the time of cold-treatment.

The process mentioned partly entails reservations being made in respect of the constancy of the $\mathrm{H}$-segments. The large segments were completely constant in the root mitoses of an individual as far as their position and number is concerned. No losses or gains of heterochromatic or euchromatic substances could be established. In this regard my investigations confirm the results of Darlington and La Cour (1940) and Haga and Kurabayashi (1953, 1954). But it is different with the shorter segments. Here, differences can be pointed 
out between identical chromosomes of different mitoses of the same plant. Such "unstable" heterochromatic regions lie mainly in the long arm of the D-chromosome (fig. I) and also at the ends of the short arm of the D- and C-chromosomes (fig. r).

Because of the difficulties the unstable segments present to analysis, I am limiting myself in this work mainly to the behaviour of the long constant regions. In fig. I, however, all the chromosomes discovered have been marked in (the unstable regions are marked $\mathrm{x}$ ). It can be seen that the number of different chromosome types, compared with

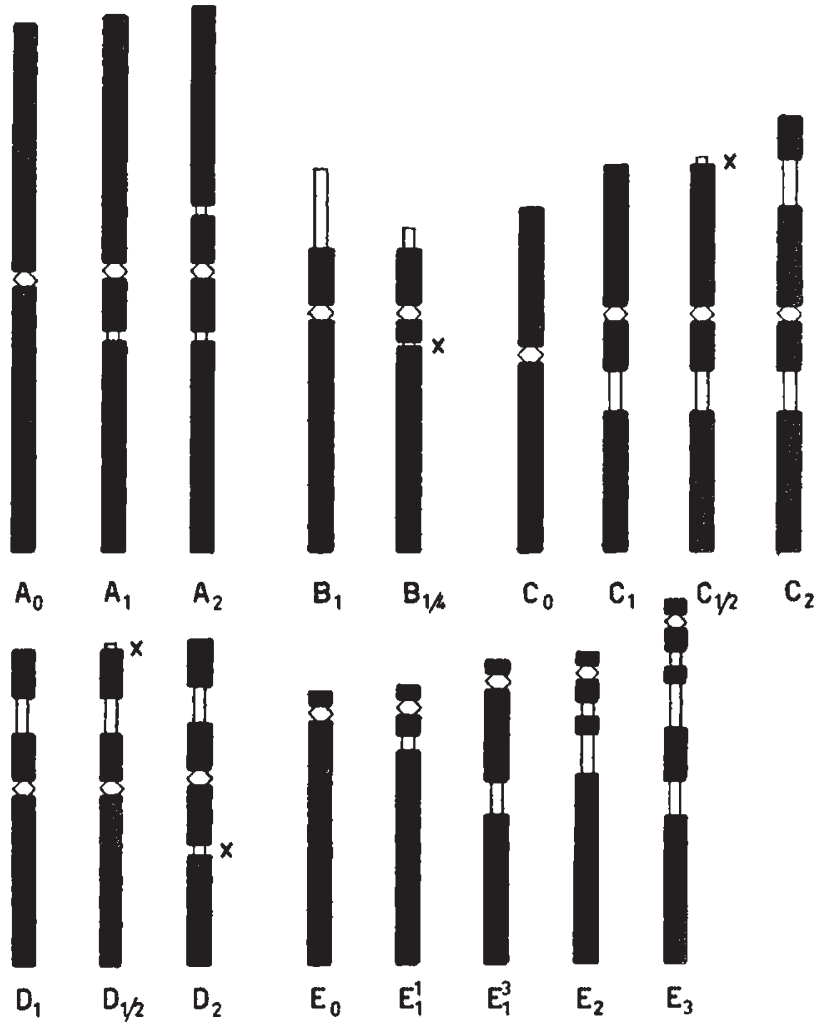

Fig. 1.-Chromosome types of T. grandiflorum (black: euchroma tic segments, white heterochromatic segments, $\mathrm{X}=$ unstable heterochromatic seg ments). $\times 2000$.

the statements of Haga and Kurabayashi (1954) for T. kamtschaticum, is small. The greatest variability is shown by the E-chromosome. In all three samples four types of E-chromosomes could be distinguished (plate, figs. I-4). They were named, $\mathrm{E}_{0}, \mathrm{E}_{1}, \mathrm{E}_{2}, \mathrm{E}_{3}$ according to the number of their H-segments. We shall go into the matter of the discovery that there are two different $\mathrm{E}_{1}$-chromosomes later ( $\mathrm{p} .3^{8}{ }_{3}$ ). Constant heterochromatic blocks occur singly or in pairs in $\mathrm{C}$-chromosomes also (plate, fig. 2). The B-chromosomes are distinguished by the length of the one terminal segment. They are named $B_{1}$ and $\mathrm{B}_{1 / 4}$ (plate, fig. 3). The A- and D-chromosomes show least variation. 
Only three types of A-chromosomes $\left(\mathrm{A}_{0}, \mathrm{~A}_{1}, \mathrm{~A}_{2}\right)$ can be distinguished with certainty. In many A-chromosomes, however, both short heterochromatic regions are not stable. All D-chromosomes possess a stable $\mathrm{H}$-segment ; all remaining $\mathrm{H}$-segments are variable. In many cases, however, the $\mathrm{H}$-segment in the long arm seems to be completely constant.

From table I it can be seen that one of the discovered chromosome types is always the most numerous. We call it the standard type, and a chromosome complement with only these types of chromosomes the standard complement. In the material examined it has the formula $\mathrm{A}_{0} \mathrm{~A}_{0} \mathrm{~B}_{1} \mathrm{~B}_{1} \mathrm{C}_{1} \mathrm{C}_{1} \mathrm{D}_{1} \mathrm{D}_{1} \mathrm{E}_{2} \mathrm{E}_{2}$.

The relative frequency of deviating chromosome types varies from group to group and is at its greatest in the GH-sample (26.2 per cent.). Similar observations have been made by Haga and Kurabayashi (1954) with bigger plant-tests with T. kamtschaticum.

The 5 chromosome types of $T$. grandiflorum are affected in different

TABLE I

Frequency of chromosome types in Trillium grandiflorum

\begin{tabular}{|c|c|c|c|c|c|c|c|c|c|c|c|c|c|c|c|}
\hline Sample & $\begin{array}{l}\text { No. of } \\
\text { plants }\end{array}$ & $\mathbf{A}_{0}$ & $A_{1}$ & $\mathrm{~A}_{2}$ & $B_{1}$ & $B_{1 / 4}$ & $\mathrm{C}_{0}$ & $\mathrm{C}_{1}$ & $\mathrm{C}_{2}$ & $E_{1}$ & $\mathrm{E}_{2}$ & $\mathrm{E}_{3}$ & $\begin{array}{c}\text { Standard } \\
\text { type }\end{array}$ & \multicolumn{2}{|c|}{$\begin{array}{l}\text { No. of aberrant } \\
\text { chromosomes }\end{array}$} \\
\hline $\begin{array}{l}\mathrm{G}_{1} \\
\mathrm{G}_{2} \\
\mathrm{GH}\end{array}$ & $\begin{array}{r}42 \\
8 \\
20\end{array}$ & $\begin{array}{l}84 \\
16 \\
24\end{array}$ & $\begin{array}{l}\ldots \\
\ldots \\
{ }_{15}\end{array}$ & $\begin{array}{c}\ldots \\
\ldots \\
I\end{array}$ & $\begin{array}{l}76 \\
15 \\
38\end{array}$ & $\begin{array}{l}8 \\
1 \\
2\end{array}$ & $\begin{array}{c}2 \\
\cdots \\
\cdots\end{array}$ & $\begin{array}{l}78 \\
16 \\
33\end{array}$ & $\begin{array}{c}4 \\
\ldots \\
7\end{array}$ & $\begin{array}{l}1 \\
6 \\
5\end{array}$ & $\begin{array}{r}82 \\
7 \\
23\end{array}$ & $\begin{array}{r}1 \\
3 \\
12\end{array}$ & $\begin{array}{r}320 \\
54 \\
\times 18\end{array}$ & $\begin{array}{c}\text { total } \\
16 \\
10 \\
4^{2}\end{array}$ & $\begin{array}{c}\text { per } \\
\text { cent. } \\
4.8 \\
15.6 \\
26.2\end{array}$ \\
\hline Total & 70 & 124 & 15 & I & 129 & II & 2 & 127 & II & 12 & IIZ & 16 & 492 & 68 & $12 \cdot I$ \\
\hline
\end{tabular}

degrees by variability. In the $\mathrm{G}_{1}$-sample it is the B- and $\mathrm{C}$-chromosome, and in the $\mathrm{G}_{2}$-sample the $\mathrm{E}$-chromosomes which vary most widely. The GH-sample shows variability in all chromosomes. In the average the E-chromosomes seem to be the most unstable, 20 per cent. of all E-chromosomes deviate from the standard type.

Darlington and La Cour discovered (1940) that even the homologous chromosomes of $\mathcal{T}$. grandiflorum can vary in heterochromatin content. Their observations were confirmed by Haga and Kurabayashi (I954) and could also be confirmed in my experiments (table 2). As is to be expected the frequency of heteromorphic chromosome pairs depends on the degree of variability of the different chromosomes (table I).

Surprisingly the number of plants with aberrant homomorphic chromosomes is relatively small. The combinations $\mathrm{E}_{1} \mathrm{E}_{1}$ and $\mathrm{E}_{3} \mathrm{E}_{3}$ appear only twice each, $\mathrm{C}_{2} \mathrm{C}_{2}$ only once. The $\mathrm{B}_{1 / 4}$-chromosome does not appear at all in a homozygous condition. This situation is analogous with that in Campanula persica (Darlington and Gairdner, 
1937) where only "basic types" are homozygous. Like the interchanges of Campanula the aberrant chromosomes of Trillium float in heterozygous combinations.

To obtain more detailed information about the relationship between heterochromatic and euchromatic regions, measurements were made of twenty chromosomes of each different type. They show that the total length of the euchromatic regions always remains about the same. Only the heterochromatin is variable.

Besides the usual chromosomes many plants in all three experimental groups possess fragment chromosomes as well. A report on their morphology and genetics was given in an earlier work (Rutishauser, 1956).

TABLE 2

Frequency of heteromorphic and homomorphic chromosome pairs

\begin{tabular}{|c|c|c|c|c|c|c|c|c|c|c|c|c|}
\hline \multirow{2}{*}{ Sample } & \multirow{2}{*}{$\begin{array}{l}\text { No. of } \\
\text { plants }\end{array}$} & \multicolumn{2}{|c|}{ A } & \multicolumn{2}{|c|}{ B } & \multicolumn{2}{|c|}{ C } & \multicolumn{2}{|c|}{ E } & \multicolumn{3}{|c|}{ Total } \\
\hline & & hom. & het. & hom. & het. & hom. & het. & hom. & het. & hom. & het. & $\begin{array}{c}\text { per } \\
\text { cent. }\end{array}$ \\
\hline $\begin{array}{l}\mathrm{G}_{1} \\
\mathbf{G}_{2} \\
\mathrm{GH}\end{array}$ & $\begin{array}{r}42 \\
8 \\
20\end{array}$ & $\begin{array}{r}42 \\
8 \\
9\end{array}$ & $\begin{array}{l}\ldots \\
\ldots \\
I I\end{array}$ & $\begin{array}{r}34 \\
7 \\
18\end{array}$ & $\begin{array}{l}8 \\
1 \\
2\end{array}$ & $\begin{array}{r}36 \\
8 \\
13\end{array}$ & $\begin{array}{r}6 \\
\ldots \\
7\end{array}$ & $\begin{array}{r}40 \\
2 \\
8\end{array}$ & $\begin{array}{r}2 \\
6 \\
12\end{array}$ & $\begin{array}{r}152 \\
25 \\
48\end{array}$ & $\begin{array}{r}16 \\
7 \\
3^{2}\end{array}$ & $\begin{array}{l}10 \\
22 \\
40\end{array}$ \\
\hline Total & 70 & 59 & $I I$ & 59 & $I I$ & $57^{*}$ & 13 & $5^{\circ} \dagger$ & 20 & 225 & 55 & 20 \\
\hline
\end{tabular}

* ${ }_{5} 6 \mathrm{C}_{1} \mathrm{C}_{1}$-pairs and $\mathrm{I}_{2} \mathrm{C}_{2} \mathrm{C}_{2}$-pair.

$\dagger 4^{6} \mathrm{E}_{2} \mathrm{E}_{2-}-2 \mathrm{E}_{1} \mathrm{E}_{1-}$ and $2 \mathrm{E}_{3} \mathrm{E}_{3}$-poirs.

\section{DEVELOPMENT OF THE EMBRYO-SAC AND THE ENDOSPERM}

The embryo-sac development of T. grandiflorum was investigated by Ernst (1902) and it was found that here was a case of the Allium type.* The same is true according to investigations of Coulter and Chamberlain (I9I5) for $T$. recurvum, according to Heatley (I9I6) for $T$. cernuum, and according to Spangler (1925) for T. sessile. The Allium type of embryo-sac development is characterised by the fact that a cell wall is formed only after the first meiotic division of the EMC (fig. 5). Two dyads are formed: the upper one degenerates. The nucleus of the lower one undergoes three further divisions, so that an 8-nuclear ES is built up. The first of these three divisions corresponds to the second meiotic division. The statement that the two polar nuclei derive from the two tetrad nuclei which develop in connection with the second meiotic division, is important for our cytological problem. As has been shown earlier (Rutishauser, I955a,b) it thus becomes possible to carry out "tetrad analysis" by investigation of endosperm mitoses.

\footnotetext{
* The accounts of Jeffrey and Haertl (1939) regarding the embryo-sac development of T. grandiflorum was proved to be erroneous by Blain and Howe (cit. from Maheshwari 1947).
} 
The course of endosperm development in $T$. grandiflorum was investigated with endosperms which were prepared in toto from seeds. Fig. 2 gives information about the sequence of the nuclear divisions in the two chambers, the chalazale and the micropylar. From the youngest observed stage on (8-nuclear endosperm) the development proceeds to the 64 -nuclei stage in such a way that the nuclei of the micropylar chamber divide first, and then the nuclei of the chalazale chamber follow. The development of the micropylar chamber seldom is further in advance : only once was an endosperm observed whose micropylar region had 32 prophase nuclei, while the chalazale was still in the 16 -nuclear stage.

From these observations it follows that the division impulse affects the micropylar chamber first, then spreads to the chalazal chamber Contrary to the suppositions of Swamy (1948) about the endosperm development of $T$. undulatum both chambers appear to be equivalent as far as the number of the nuclei is concerned. On the other hand differences of another kind appear quite early. The chalazal chamber is lower than the micropylar one even in the earliest observed stage, the nuclei therefore lie closer together. This difference is strengthened

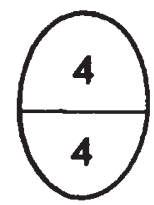

2

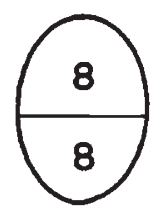

5

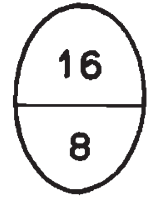

1

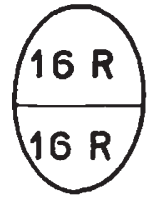

1

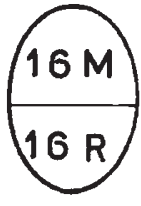

3

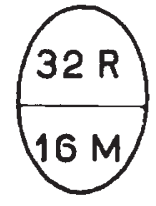

7

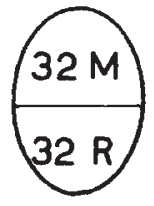

1

Fic. 2.-Endosperm development of $T$. grandiflorum. $\mathbf{M}=$ mitoses, $\mathrm{R}=$ resting nuclei. Below, number of observations.

with the growth of the endosperm. The most striking difference concerns the reaction to leuco-basic fuchsin : the nuclei of the chalazal chamber are always much more deeply stained than those of the micropylar ones.

The abnormal behaviour of the chromosomes under the influence of cold presumably stands in close relation to this property of the chalazal endosperm nuclei. In the chromosomes of the chalazal endosperm the starvation effect is much less marked than in the chromosomes of the micropylar nuclei. The $\mathrm{H}$-segments are as a rule more darkly stained and in many chalazal mitoses the differential effect is completely absent.

These observations are of great interest because they possibly hold the key to the understanding of further abnormal processes which are mostly connected with the chalazal region of the endosperm. As Swamy (1948) has already stated for $T$. undulatum and a whole series of embryologists before him for plants with helobial development of the endosperm, irregular divisions and nuclei of dissimilar sizes occur in the chalazal chamber. The favourable cytological properties 
of $T$. grandiflorum permit a closer acquaintance with the nature of these two phenomena. Counts of metaphases show that polyploid chromosome numbers are relatively frequent. Metaphases with $6 n=30,9^{n}=45$, and $\mathrm{I} 2 n=60$ could be observed. The chromosomes of these polyploid metaphases appear to be unchanged, as far as the insufficient starvation effect permits such an analysis. Presumably it is a matter of products of endomitotic divisions.

A second abnormality in the behaviour of the mitoses is shown particularly in the anaphases and telophases. Very frequently bridges and dumb-bell shaped nuclei are observed which prove that spontaneous chromosome breakage and reunions are not rare. It is possible that such persistent bridges occasionally give rise to the formation of polyploid nuclei.

Spontaneous chromosome breakage and polyploid mitoses also appear in the micropylar endosperm, but there they are rarer. In respect of these two phenomena there is consequently only a difference in degree.

The divergence between the chalazal and micropylar endosperm is accentuated with the increasing age of the seeds insofar that the intensity of division of the micropylar nuclei is significantly greater than that of chalazal. And the capacity for division lasts longer there. The micropylar endosperm therefore grows more quickly and also attains a greater bulk. With the beginning of the cell-wall formation, which can be seen only imperfectly in our leuco-basic fuchsin preparations, the mitoses cease to be simultaneous. They are irregularly scattered through the endosperm and their distribution is the same as in the meristems of the root-tip. The end of the synchronisation of the mitoses begins sooner in the chalazal chamber, which presumably means that the cell-wall formation starts sooner.

\section{CYTOLOGY OF THE ENDOSPERM}

\section{(a) Metamorphosis of heterochromatin}

In the resting nucleus, both with and without cold-treatment, there appear strongly stained chromocentres whose number varies from cell to cell. Darlington and La Cour (194I) assume that it is a question of the interkinetic condition of the H-segments. Their assumption was confirmed by the researches of Kurabayashi (1952b). According to him the larger chromocentres represent fusion products in which the $\mathrm{H}$-segments of several chromosomes take part. So it is understandable that the number of chromocentres is variable and does not correspond to the number of heterochromatic blocks. The results of my own investigations are in close agreement with this discovery. Counts of chromocentres show that their proportion in the nuclei of the triploid endosperm and the diploid root cells is approximately $3: 2$.

In the endosperm preparations the $\mathrm{H}$-segments of the prophase chromosomes are drawn out into very long thin threads (fig. 3). 
These stages could not be observed in the cold-treated root-tip cells or in endosperm prophases at normal temperature. Two conclusions may be drawn :

(I) The long thin threads represent a cold effect which means that the spiralisation of the early prophase chromosome does not take place in the H-segments.
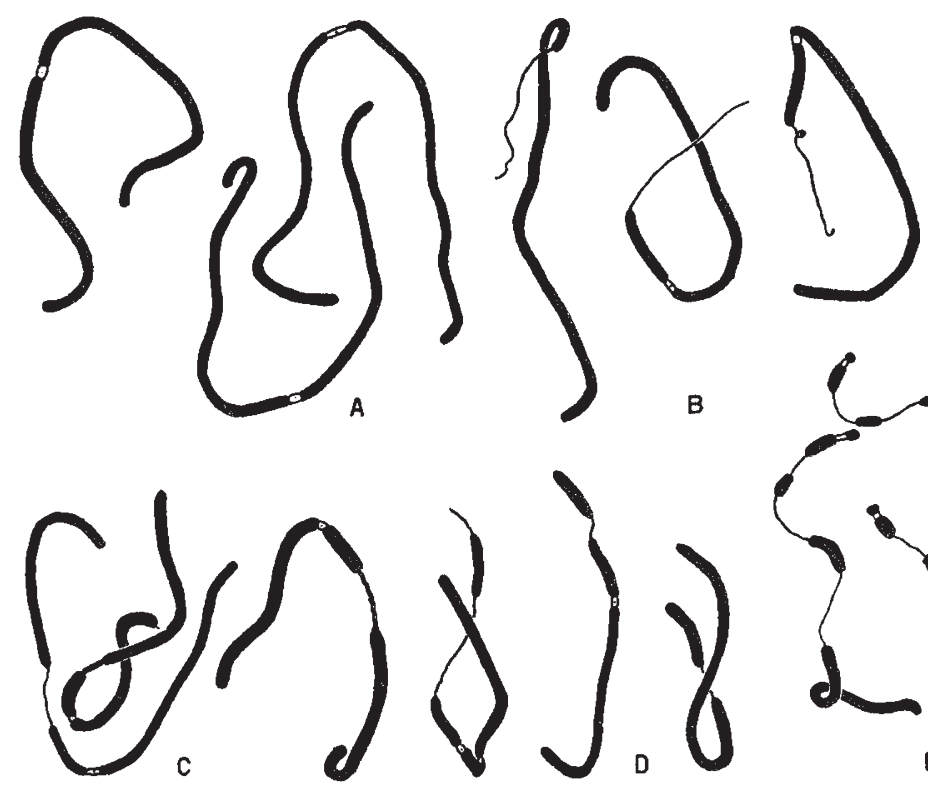

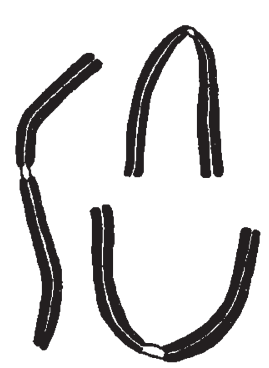

A

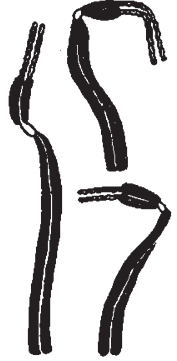

B

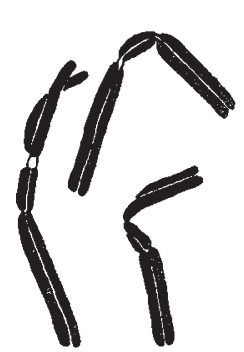

C
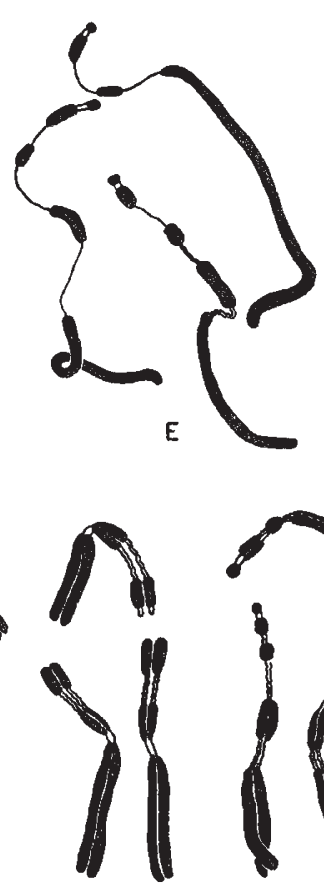

D

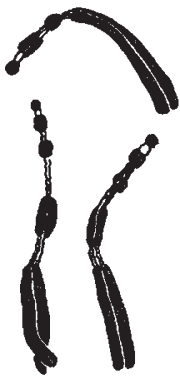

E

FIG. 3.-Chromosomes of chilled endosperms. Upper two rows : the 15 chromosomes of a late prophase. Third row : the 15 chromosomes of a metaphase plate. $\times 1250$.

(2) The difference between the cold-treated prophases of the root meristem and the endosperm indicates that the behaviour of the heterochromatin is determined not only by the temperature but also by the immediate environment of the chromosomes.

The uncoiled state of the H-segments lasts throughout the prometaphase. Not until shortly before the metaphase do the H-segments 
become shorter and thicker, but they never attain the same degree of condensation as in the root mitoses. And so the coiling apparently begins later and is not complete. Although the $\mathrm{H}$-segments are now thicker than in the prophase, their stainability does not increase and so the difference in staining intensity between euchromatin and heterochromatin does not depend on differences in spiralisation. It is rather to be ascribed to a reduction in DNA content, as Darlington and La Cour (1940) have suggested.

It can clearly be seen from fig. 3 that the long thin segments of the prophase chromosomes correspond to the unstained regions of the metaphase chromosomes. There all chromosomes of a prophase and a metaphase which lie in the same endosperm have been drawn. The endosperm has the chromosome complement $A_{0} A_{0} A_{0} B_{1} B_{1} B_{1} C_{1} C_{1} C_{1}$ $\mathrm{D}_{1} \mathrm{D}_{1} \mathrm{D}_{\frac{1}{2}} \mathrm{E}_{2} \mathrm{E}_{3} \mathrm{E}_{3}$.

The reduced spiralisation in the $\mathrm{H}$-segments of the prophase and metaphase chromosomes presumably is the reason that small $\mathrm{H}$ segments are often more clearly visible in the endosperm chromosomes than in the metaphase chromosomes of the root-tips. The difference is greatest in the young endosperm.

\section{(b) Distribution of chromosomes}

The great variability of the $\mathrm{H}$-segments of different individuals of the same sample stands in sharp contrast to their constancy within the root-tips of the same plant. Apart from the unstable H-segments only slight differences have been found between corresponding chromosomes of different mitoses, in relation to the extent of the heterochromatic blocks. Differences in their number and position do not appear at all. The question therefore arises whether the $\mathrm{H}$-segments are changed in the course of seed formation and fertilisation and how the variability of the Trillium chromosomes arises. To decide this question individuals of $T$. grandiflorum were crossed and the $F_{1}$-endosperms tested. It is to be noted in all these tests that:

(I) the seed plants contribute two chromosome-sets to the chromosome complement of the endosperm nuclei, and that

(2) these two sets, because of the Allium type of the embryo-sac development, derive from a single dyad-cell.

Forty crosses were made and the chromosome complements of 7 I 7 endosperms were ascertained. The number of all chromosomes investigated was 33,354. They were distributed among 2207 mitoses. For the question of the constancy of heterochromatin the crosses between plants with homomorphic chromosomes are of especial importance. If we for the time being disregard the phenomena of spontaneous chromosome breakage (which is treated in a special chapter) it appears from my investigations that the $\mathrm{H}$-segments are carried over exactly like the euchromatic segments, with astonishing regularity. In number and position the large $\mathrm{H}$-segments always correspond exactly to those 
in the root meristems. They undergo no change in this respect in the course of meiosis and gamete formation.

On the other hand occasional extra H-segments appeared in the course of endosperm development. Among more than $6000 \mathrm{E}_{2}$ chromosomes of the cross $\mathrm{E}_{2} \mathrm{E}_{2} \times \mathrm{E}_{2} \mathrm{E}_{2}$ six such aberrations were found. The most frequent are shown in fig. $7 \mathrm{E}, b$. They reveal, besides the two normal H-segments, a short extra heterochromatic part that is inserted at the proximal end of the distal euchromatic region. The origin of the extra heterochromatic region can in these cases not be ascertained. However it is very probable that it is a question of an inversion ( $c f$. Haga and Kurabayashi, r954).

The two abnormal chromosomes in fig. $7 \mathrm{E}, c$ and $8 c$ represent $\mathrm{E}_{3}$-chromosomes. Their extra $\mathrm{H}$-segment is exactly in the position occupied by the third $\mathrm{H}$-segment in normal $\mathrm{E}_{3}$-chromosomes. The discovery is worth noting that many $E_{2}$-chromosomes of the same

TABLE 3

Non-disjunction in endosperms of Trillium grandiflorum ( $3 \mathrm{x}=15)$

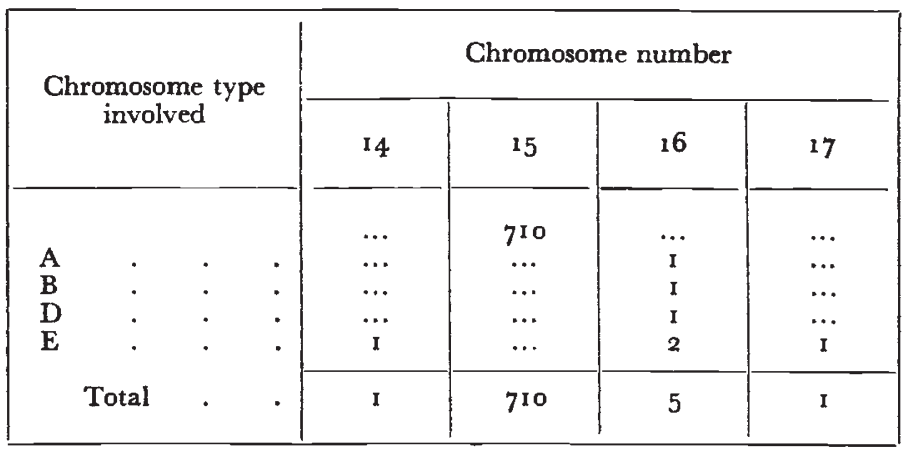

cross show a small incision in the same place. As the extra heterochromatic blocks are fairly broad, they can hardly be regarded as unstable H-segments, which have become visible because of uncoiling. We are rather inclined to interpret them as duplications of small heterochromatic regions already existing. Similar chromosome aberrations can also be observed in the G- and D-chromosomes. But they always appear singly only.

Non-disjunction. A striking, if very rare abnormality in behaviour is that, occasionally in an endosperm, 14,16 or 17 chromosomes appear instead of the triploid number I5 (table 3 ). In all mitoses of such endosperms the same chromosome was always present in either the more numerous or the less numerous group. Four times the E-chromosome is concerned, the A-, B- and D-chromosomes once each (fig. $4 a, c$ ). The deviation can be explained by assuming that in the process of gamete formation non-disjunction has taken place. For the endosperms with 5 E-chromosomes (fig. $4 b$ ) it can be deduced with certainty that this procedure has taken place during the first 
meiotic division of the EMC. If 2 E-chromosomes reach the surviving dyad cell, then all nuclei of the female gametophyte (including the two polar nuclei) each contain 2 E-chromosomes. In the endosperm
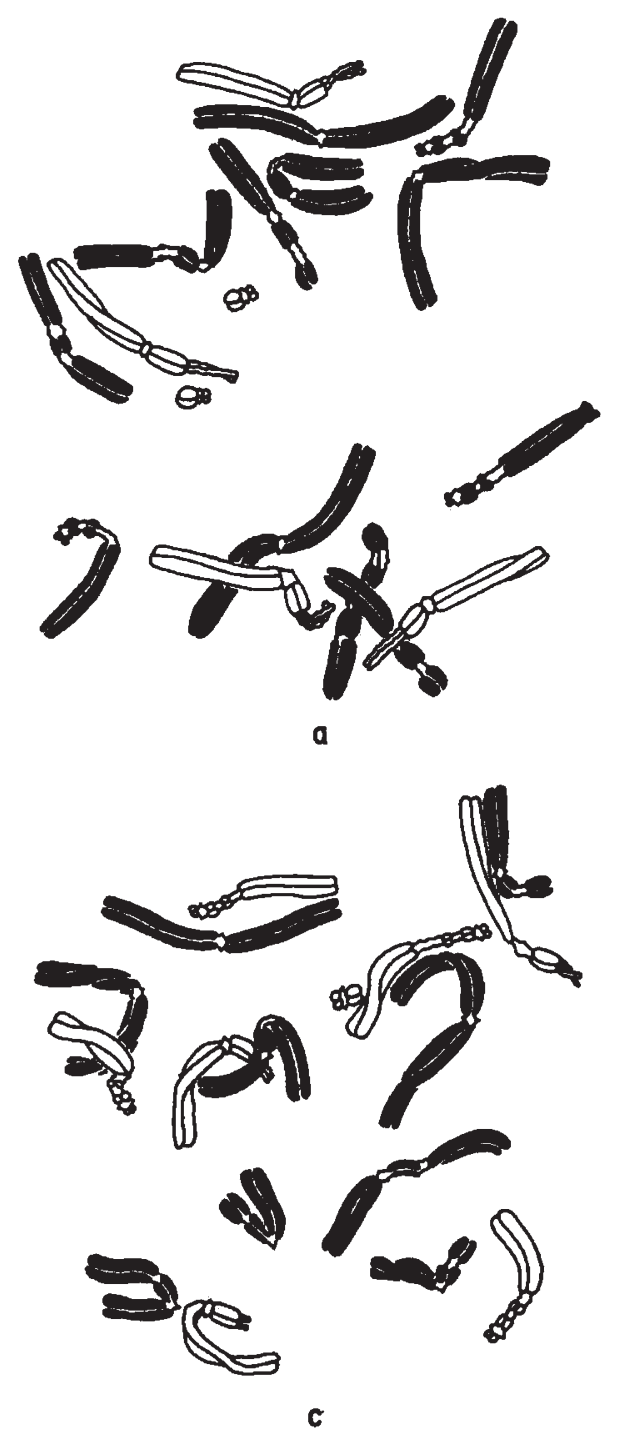

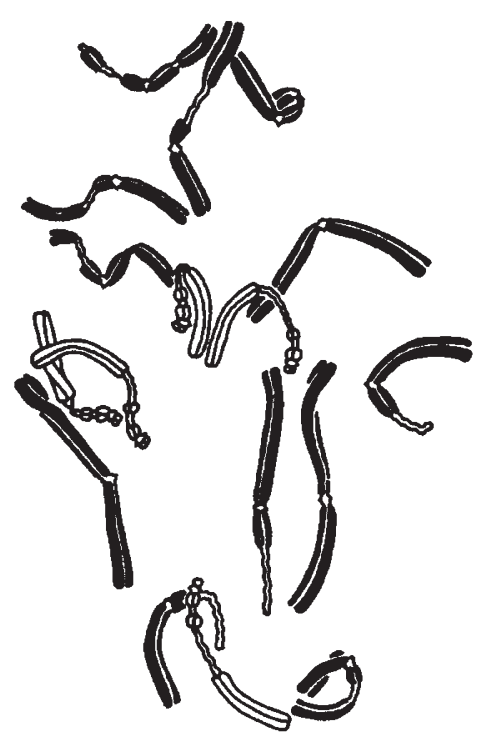

b

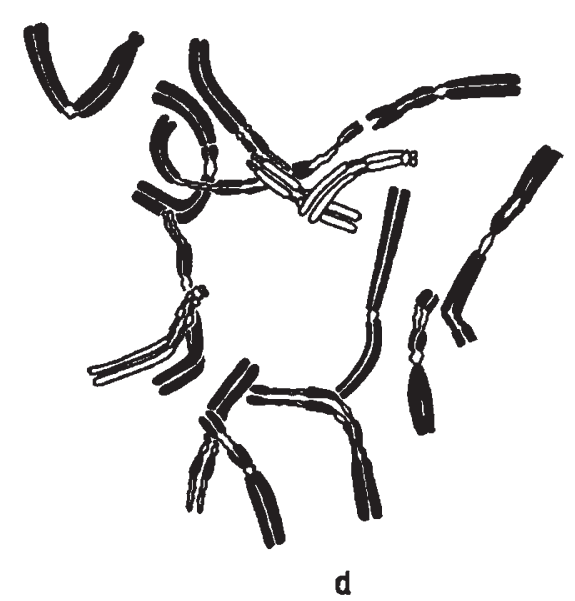

Fig, 4.-Metaphases of chilled endosperms :- $(a, c)$ Non-disjunction on the male side, involving the B-chromosome $(a)$ and the E-chromosome $(c) . \quad(b)$ Non-disjunction on the female side ( 5 instead of 3 E-chromosomes). (d) Metaphase of the cross $\mathbf{E}_{1} \mathrm{E}_{2} \times \mathrm{E}_{2} \mathrm{E}_{2}$ with two $\mathrm{E}_{1}^{3}$ - and one $\mathrm{E}_{2}$-chromosomes. In $(a)$ two, in $(c)$ one fragment chromosome. $\times 1000$.

then there must be 5 of them present, 4 from the female side and one from the male side. All endosperms with 14 or 16 chromosomes respectively, indicate non-disjunction on the male side and all endosperms with 17 chromosomes, non-disjunction on the female side. 
The ratio discovered $(6: 1)$ indicates that in the course of pollen development more non-disjunction takes place, or else that supernumerary chromosomes are tolerated more readily in the pollen grains.

During the endosperm development non-disjunction also takes place. Occasionally mitoses with 14 or 16 chromosomes appear together with those which contain I5. But as there is always the danger of displacement of chromosomes in squash-preparations of tissues whose cells form only very thin membranes, somatic nondisjunction has not been quantitatively investigated.

Distributions of heteromorphic chromosomes and crossing-over. Crosses between plants with heteromorphic chromosome pairs must give

TABLE 4

Chromosome distribution of heteromorphic chromosome pairs.

(a) Male plant heterozygote

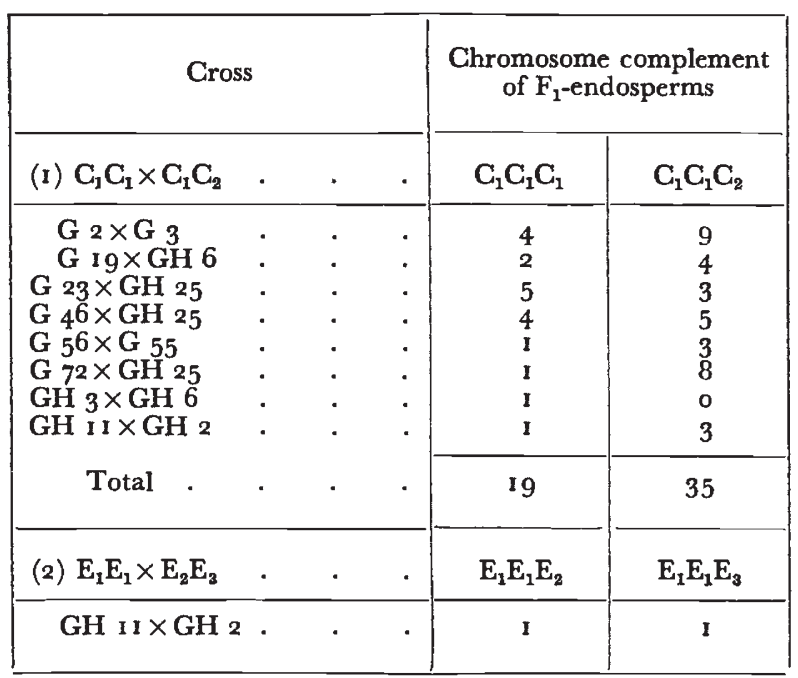

different results, according to whether the male or the female plant contains the heteromorphic pair.

Since 4 microspores develop from meiosis, each male gamete contains only one of the 4 chromatids of a bivalent. The pollen grains of a $\mathrm{C}_{1} \mathrm{C}_{2}$ plant for example should therefore be half $\mathrm{C}_{1}$ and half $\mathrm{C}_{2}$. In a cross of the type $\mathrm{C}_{1} \mathrm{C}_{1} \times \mathrm{C}_{1} \mathrm{C}_{2}$ one would have to expect endosperms with the chromosome complement $\mathrm{C}_{1} \mathrm{C}_{1} \mathrm{C}_{1}$ and $\mathrm{C}_{1} \mathrm{C}_{1} \mathrm{C}_{2}$ in equal numbers. The only cross of this type which permitted enough analyses, $\mathrm{C}_{1} \mathrm{C}_{1} \times \mathrm{C}_{1} \mathrm{C}_{2}$, proved extremely abnormal : I 9 endosperms $\mathrm{C}_{1} \mathrm{C}_{1} \mathrm{C}_{1}$ oppose 35 endosperms $\mathrm{C}_{1} \mathrm{C}_{1} \mathrm{C}_{2}$. The deviation from the ratio I $: I$ is significant $(P<0.0 I)$. It cannot be ascertained whether this deviation results from competition between $\mathrm{C}_{1}$ and $\mathrm{C}_{2}$ gametes or whether the viability of the endosperms depends to a certain extent on the chromosome constitution. Whichever influence is effective, one thing seems to be clear: the difference between the two 
G-chromosomes, which presumably concerns their heterochromatin content has a clearly demonstrable physiological effect. Pollen grains or endosperms with a $\mathrm{C}_{2}$-chromosome are favoured.

The results of the crosses between seed-plants with heteromorphic, and pollen plants with homomorphic, chromosomes permit a quantitative analysis. In part these results have been published elsewhere

TABLE 5

Chromosome distribution of heteromorphic chromosome pairs.

(b) Female plant heterozygote

\begin{tabular}{|c|c|c|c|c|}
\hline Cross & \multicolumn{3}{|c|}{$\begin{array}{c}\text { Chromosome complement of } \\
\mathrm{F}_{1} \text {-endosperms }\end{array}$} & $\begin{array}{l}\text { Frequency of } \\
\text { post-reductions } \\
\text { per cent. }\end{array}$ \\
\hline (I) $\mathrm{C}_{1} \mathrm{C}_{2} \times \mathrm{C}_{1} \mathrm{C}_{1}$ & $\mathrm{C}_{1} \mathrm{C}_{1} \mathrm{C}_{1}$ & $\mathrm{C}_{1} \mathrm{C}_{1} \mathrm{C}_{2}$ & $\mathrm{C}_{1} \mathrm{C}_{2} \mathrm{C}_{2}$ & \\
\hline 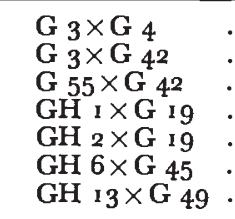 & $\begin{array}{c}3 \\
6 \\
\ldots \\
\ldots \\
1 \\
\ldots\end{array}$ & $\begin{array}{r}20 \\
15 \\
27 \\
1 \\
4 \\
7 \\
4\end{array}$ & $\begin{array}{r}3 \\
4 \\
7 \\
1 \\
\ldots \\
2 \\
\ldots\end{array}$ & $\begin{array}{l}\ldots \\
\ldots \\
\ldots \\
\ldots \\
\ldots \\
\ldots\end{array}$ \\
\hline Total . & ro & 78 & 17 & 74 \\
\hline (2) $\mathrm{E}_{2} \mathrm{E}_{3} \times \mathrm{E}_{2} \mathrm{E}_{2}$ & $\mathrm{E}_{2} \mathrm{E}_{2} \mathrm{E}_{2}$ & $\mathrm{E}_{2} \mathrm{E}_{2} \mathrm{E}_{3}$ & $\mathrm{E}_{2} \mathrm{E}_{3} \mathrm{E}_{3}$ & $\ldots$ \\
\hline 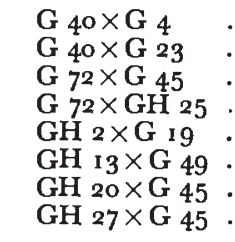 & $\begin{array}{r}3 \\
2 \\
4 \\
1 \\
1 \\
\ldots \\
\cdots \\
2 \\
2\end{array}$ & $\begin{array}{r}8 \\
6 \\
11 \\
5 \\
3 \\
\cdots \\
1 \\
\ldots\end{array}$ & $\begin{array}{r}6 \\
\ldots \\
3 \\
3 \\
\ldots \\
3 \\
1 \\
\ldots\end{array}$ & $\begin{array}{l}\ldots \\
\cdots \\
\cdots \\
\ldots \\
\ldots \\
\cdots \\
\cdots\end{array}$ \\
\hline Total . & 13 & 34 & 16 & 54 \\
\hline (3) $\mathrm{B}_{1} \mathrm{~B}_{/ 4} \times \mathrm{B}_{1} \mathrm{~B}_{1}$ & $\mathrm{~B}_{1} \mathrm{~B}_{1} \mathrm{~B}_{1}$ & $\mathrm{~B}_{1} \mathrm{~B}_{1} \mathrm{~B}_{1 / 4}$ & $\mathrm{~B}_{1} \mathrm{~B}_{1 / 4} \mathrm{~B}_{1 / 4}$ & $\ldots$ \\
\hline G $23 \times G_{3} 6$ & 4 & 57 & 7 & 84 \\
\hline
\end{tabular}

(Rutishauser, I955a,b). But as several further cross experiments of this type have been analysed in the meantime, all results have been collated again in table 5. In all 3 cross combinations endosperms of the type A A A, A A a and A a a appear, where A stands for the $\mathrm{B}_{1}, \mathrm{C}_{1}$ or $\mathrm{E}_{2}$ chromosome, a for $\mathrm{B}_{1 / 4}, \mathrm{C}_{2}$ or $\mathrm{E}_{3}$. The appearance of 3 endosperm types can only be understood if we assume that :

(I) in the course of meiosis crossing-over takes place between the centromere and the point of the two homologous chromosomes where the difference begins, and

(2) that the division products of the first meiotic division are not separated, or, in our case, reunite after separation. 
Fig. 5 reproduces these processes which take place during meiosis and embryo-sac development. The cross $\mathrm{E}_{2} \mathrm{E}_{3} \times \mathrm{E}_{2} \mathrm{E}_{2}$ was chosen as an example ( $c f$. also Rutishauser, 1955a,b).

Respecting the position of the chiasmata two possibilities are conceivable :

(I) An exchange takes place between the centromere and the difference. This is the case, according to the chiasma type theory, when a chiasma is in the section. Then two chromatids $\mathrm{E}_{2} \mathrm{E}_{3}$ reach the two dyad nuclei. They are separated (post-reduction) in the second meiotic division (which corresponds to the first step of division in embryosac development) but reunite again at the fusion of the polar nuclei. An $\mathrm{E}_{2}$-chromosome is supplied by the spermnucleus, and so all endosperms have the chromosome complement $\mathrm{E}_{2} \mathrm{E}_{2} \mathrm{E}_{3}$.

(2) In the chromosome part which is bounded by the centromere and the place where the difference begins, there is no exchange. The chiasmata lie outside this section. Then either two $E_{2}$ or two $E_{3}$ chromatids (pre-reductions) reach the surviving dyad cells. All nuclei of the embryo-sac consequently contain only $E_{2^{-}}$or only $E_{3^{-}}$-chromosomes. After fertilisation with an $\mathrm{E}_{2}$-chromosome endosperms with the constitution $\mathrm{E}_{2} \mathrm{E}_{2} \mathrm{E}_{2}$ or $\mathrm{E}_{2} \mathrm{E}_{3} \mathrm{E}_{3}$ must be expected in equal numbers.

As can be seen from table 5 that is the case, at least as far as the cross $E_{2} E_{3} \times E_{2} E_{2}$ is concerned. The pre-reduction types of the cross $\mathrm{C}_{1} \mathrm{C}_{2} \times \mathrm{C}_{1} \mathrm{G}_{1}$ (the $\mathrm{G}_{1} \mathrm{G}_{1} \mathrm{G}_{1}$ and the $\mathrm{C}_{1} \mathrm{G}_{2} \mathrm{C}_{2}$ endosperms) do not deviate noticeably from the ratio $\mathrm{I}: \mathrm{I}(\mathrm{P}<\mathrm{O} \cdot \mathrm{OI})$. But it is striking that the number of the endosperms which carry double quantities of $\mathrm{C}_{2}$-chromosomes and which therefore derive from a central cell $\mathrm{C}_{2} \mathrm{G}_{2}$, is higher than that of the $\mathrm{C}_{1} \mathrm{G}_{1} \mathrm{C}_{1}$-endosperm.

It is to be seen that it is possible to deduce from the chromosome constitution of the endosperms whether the heteromorphic chromosome pairs have been pre- or post-reduced. All $E_{2} E_{2} E_{2}-$ and $E_{2} E_{3} E_{3}-$ endosperms arise through pre-reduction, but the $\mathrm{E}_{2} \mathrm{E}_{2} \mathrm{E}_{3}$-endosperms through post-reduction.

The results of the crosses between plants with heteromorphic and homomorphic chromosome pairs can be checked by cross experiments on plants which are both heterozygote in the same chromosome pair. On the basis of the cross results given above, four different $F_{1}$-endosperms must appear, in the cross experiment $\mathrm{C}_{1} \mathrm{C}_{2} \times \mathrm{C}_{1} \mathrm{G}_{2}$ for example $\mathrm{C}_{1} \mathrm{G}_{1} \mathrm{G}_{1}, \mathrm{C}_{1} \mathrm{C}_{1} \mathrm{G}_{2}, \mathrm{C}_{1} \mathrm{G}_{2} \mathrm{G}_{2}$ and $\mathrm{C}_{2} \mathrm{G}_{2} \mathrm{G}_{2}$ (table 6).

Both homozygous endosperms $\mathrm{C}_{1} \mathrm{C}_{1} \mathrm{C}_{1}$ and $\mathrm{C}_{2} \mathrm{C}_{2} \mathrm{G}_{2}$ as well as both heterozygote endosperms $\mathrm{G}_{1} \mathrm{C}_{1} \mathrm{C}_{2}$ and $\mathrm{G}_{1} \mathrm{G}_{2} \mathrm{C}_{2}$ should appear in the ratio I : I. The number of post-reductions can be calculated from 
this cross combination also. As is shown in table 6, only the heterozygous endosperms of the middle column are post-reductions. In the total number of the $\mathrm{C}_{1} \mathrm{G}_{1} \mathrm{G}_{2}$-endosperms as well as in the total
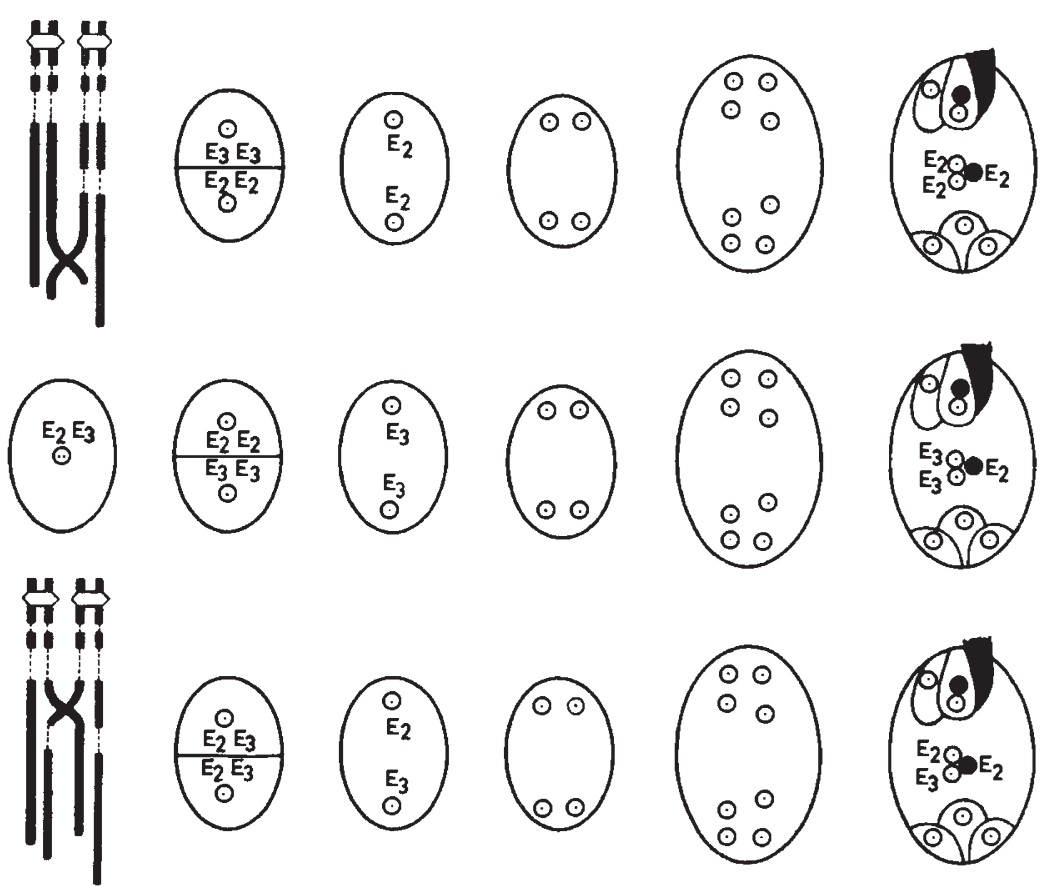

Frc. 5.-Embryo-sac development of $T$. grandiflorum (Allium-type) showing distribution of heteromorphic chromosome pairs (see text).

number of the $\mathrm{C}_{1} \mathrm{C}_{2} \mathrm{C}_{2}$-endosperms there are included also prereductions. Their number is the same as the number of homozygous endosperms. It follows that the number of post-reductions can be

TABLE 6

Chromosome complements of $F_{1}$-endosperms of the cross $C_{1} C_{2} \times C_{1} C_{2}$

\begin{tabular}{|l|l|l|l|}
\hline & & & \\
\hline $\mathrm{C}_{1}$ & $\mathrm{C}_{1}$ & $\mathrm{C}_{1} \mathrm{C}_{2}$ & $\mathrm{C}_{2} \mathrm{C}_{2}$ \\
\hline $\mathrm{C}_{2}$ & $\mathrm{C}_{1} \mathrm{C}_{1} \mathrm{C}_{1}$ & $\mathrm{C}_{1} \mathrm{C}_{1} \mathrm{C}_{2}$ & $\mathrm{C}_{2} \mathrm{C}_{2} \mathrm{C}_{2}$ \\
$\mathrm{C}_{1} \mathrm{C}_{1} \mathrm{C}_{2}$ & $\mathrm{C}_{2} \mathrm{C}_{2} \mathrm{C}_{2}$ & $\mathrm{C}_{2} \mathrm{C}_{2} \mathrm{C}_{2}$ \\
\hline
\end{tabular}

(Post reductions are printed in heavy type)

calculated from the difference between the sum of all heterozygous endosperms and the sum of all the homozygous ones. The number of endosperms obtained by crosses of this type is still very small. As table 7 shows, all four expected chromosome complements nevertheless appear. 
The frequency of post-reductions arrived at in table 7 amounts to 57 per cent. It does not agree with the value found for the cross $\mathrm{C}_{1} \mathrm{C}_{2} \times \mathrm{C}_{1} \mathrm{C}_{1}$. But the difference is not significant $(\mathrm{P}>0.0 \mathrm{I})$. Further investigations will show whether agreement between the two crosscombinations is present or not.

\section{TABLE 7}

Chromosome distribution of heteromorphic chromosome puirs.

(c) Both plants heterozygote

\begin{tabular}{|c|c|c|c|c|c|c|}
\hline Cross & & \multicolumn{4}{|c|}{$\begin{array}{l}\text { Chromosome complement of } \\
F_{1} \text {-endosperms }\end{array}$} & \multirow[t]{2}{*}{$\begin{array}{l}\text { Frequency of } \\
\text { post-reductions } \\
\text { per cent. }\end{array}$} \\
\hline (1) $\mathrm{C}_{1} \mathrm{C}_{2} \times \mathrm{C}_{1} \mathrm{C}_{2}$ & & $\mathrm{C}_{1} \mathrm{C}_{1} \mathrm{C}_{1}$ & $\mathrm{C}_{1} \mathrm{C}_{1} \mathrm{C}_{2}$ & $\mathrm{C}_{1} \mathrm{C}_{2} \mathrm{C}_{2}$ & $\mathrm{C}_{2} \mathrm{C}_{2} \mathrm{C}_{2}$ & \\
\hline GH $6 \times \mathrm{GH}_{25}$ & . & 2 & 5 & 3 & $\ldots$ & $\ldots$ \\
\hline GH $22 \times \mathrm{GH}_{2}$ & . & $\ldots$ & 2 & I & I & $\ldots$ \\
\hline Total & . & 2 & 7 & 4 & I & 57 \\
\hline
\end{tabular}

From the results obtained with B-, C- and E-chromosomes it is evident that chiasmata are formed between the centromere and the place where the difference of the two heteromorphic chromosomes begins. Naturally, it is possible to measure these regions. The measurements are given in table 8 together with the corresponding values for the post-reductions.

TABLE 8

Comparison of the frequency of post-reductions and the measured centromere distance

\begin{tabular}{|c|c|c|c|}
\hline \multirow{2}{*}{ Chromosome } & \multicolumn{2}{|c|}{$\begin{array}{c}\text { Length of measured } \\
\text { centromere distance }\end{array}$} & $\begin{array}{c}\text { Frequency of } \\
\text { post-reductions } \\
\text { per cent. }\end{array}$ \\
\cline { 2 - 4 } eu+het & eu & \\
\hline B & 4.3 & $3 \cdot 1$ & 84 \\
C & $8 \cdot 1$ & 5.6 & 74 \\
E & 10.9 & $5 \cdot 4$ & 56 \\
\hline
\end{tabular}

As can be seen, there is no parallel between the frequency of postreductions and the length of the measured centromere-distance, either the total length, or that of the euchromatic regions alone. Indeed the highest value coincides with the shortest distance. From these comparisons it is evident that the number of post-reductions does not tell us anything about the absolute length of the measured 
centromere-distance, when various chromosomes are compared with one another. An agreement is only to be expected, as Darlington and Dark (1932) and Mather (1935) have already indicated, when the chiasmata happen to be distributed at random over the chromosomes. Reduction of the number of chiasmata or localisation of the chiasmata would essentially alter the picture.

The question of the position of the chiasmata could be solved if heteromorphic chromosome pairs were used which showed simultaneous differences in several places. Plants with such chromosome pairs occurred very rarely in my samples. One of them, $\mathrm{GH} 3$, showed heteromorphic chromosomes of the type $\mathrm{E}_{0} \mathrm{E}_{3}$ (plate, fig. I). It was crossed onto a plant with the chromosome constitution $\mathrm{E}_{2} \mathrm{E}_{2}$. Of

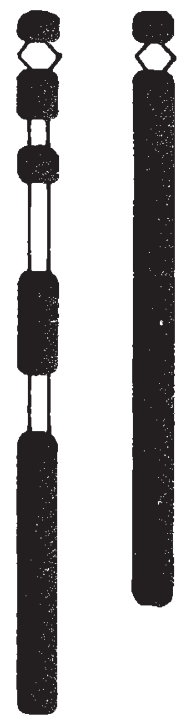

$E_{3} \quad E_{0}$

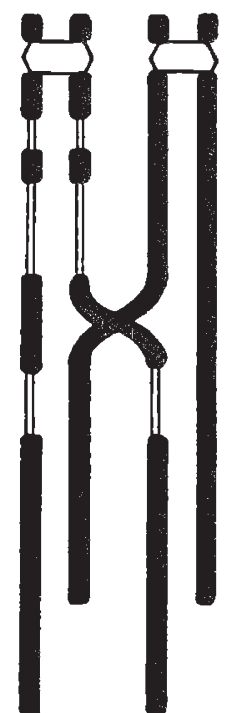

$E_{3} E_{0} E_{3} E_{0}$
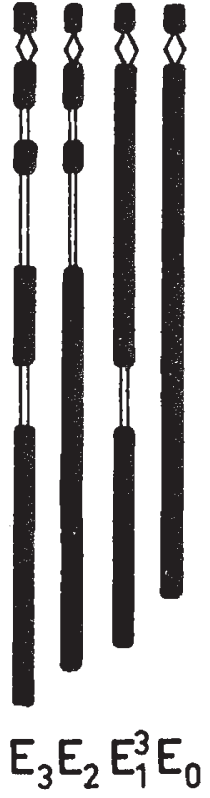

Fig. 6.-Formation of new chromosome types by crossing-over (see text).

the I I endosperms which could be analysed in relation to the Echromosome, Io had the constitution $\mathrm{E}_{2} \mathrm{E}_{2} \mathrm{E}_{3}$, and the eleventh endosperm showed a single strongly polyploid metaphase, in which a new $E_{1}$-chromosome appeared which could be found in neither of the two parents.

The same plant $\mathrm{GH}_{3}$ was also crossed onto Paris quadrifolia. In one of the endosperms, whose mitoses contained 20 Paris and 5 Trillium chromosomes, the same chromosome could be observed again. It displays a single heterochromatic region, which lies in the place where in the $E_{3}$-chromosomes the most distal $H$-segment can be found (fig. $4 d$ ). There can be no doubt that it owes its origin to a chiasma which lay in the third euchromatic region ( $c f$. scheme, fig. 6).

Unfortunately the number of tests is still too small to estimate 
the frequency of the chiasmata in the various euchromatic regions of the E-chromosomes. However they show that the chromosomes with a greater number of $\mathrm{H}$-segments are more easily transmitted than the others. Of a total of I I endosperms which developed from a cross of $\mathrm{GH}_{3}$ and other Trillium specimens, Io displayed the $\mathrm{E}_{3}$ chromosome and only one the new $\mathrm{E}_{1}{ }^{3}$-chromosome.

It has been shown earlier (p. 369) that in the test plants of the $\mathrm{GH}$ sample two different $\mathrm{E}_{1}$-chromosomes appear (fig. I). One possesses a very short and often unstable heterochromatic region near the centromere; the $\mathrm{H}$-segment of the other one, however, takes the place occupied by the third $\mathrm{H}$-segment of the $\mathrm{E}_{3}$-chromosome. This second type $\left(\mathrm{E}_{1}{ }^{3}\right)$ corresponds with the $\mathrm{E}_{1}$-chromosomes which developed from crossing-over. It is therefore very likely that it has the same origin. This interpretation is supported by the fact that in the same sample and only there $\mathrm{E}_{0} \mathrm{E}_{3}$-complements are also found. The abnormal $\mathrm{E}_{1}{ }^{3}$-chromosome was found in two plants, one together

\section{Plate}

FIGs. I $* 4 .-$ Metaphases of chilled root-tips.

Fig. I.-Chromosome complement $\mathrm{A}_{0} \mathrm{~A}_{0} \mathrm{~B}_{1} \mathrm{~B}_{1} \mathrm{C}_{1} \mathrm{C}_{1} \mathrm{D}_{1} \mathrm{D}_{1} \mathrm{E}_{0} \mathrm{E}_{8}, \mathrm{E}_{8}$ at 3 o'clock, $\mathrm{E}_{0}$ on the left. Fig. 2.-Chromosome complement $\mathrm{A}_{0} \mathrm{~A}_{1} \mathrm{~B}_{1} \mathrm{~B}_{1} \mathrm{C}_{1} \mathrm{C}_{2} \mathrm{D}_{1} \mathrm{D}_{2} \mathrm{E}_{1}{ }^{2} \mathrm{E}_{3}, \mathrm{C}_{1} \mathrm{C}_{2}$ at 9 o'clock, $\mathrm{E}_{1}^{3}$ at 10 o'clock, $E_{3}$ at is o'clock, $A_{1}$ centre.

FIG. 3.-Chromosome complement $\mathrm{A}_{0} \mathrm{~A}_{0} \mathrm{~B}_{1} \mathrm{~B}_{1} / \mathrm{C}_{1} \mathrm{C}_{1} \mathrm{D}_{1} \mathrm{D}_{2} \mathrm{E}_{2} \mathrm{E}_{2}, \mathrm{~B}_{1} / 4$ at 7 o'clock.

Fig. 4-Chromosome complement $A_{0} A_{1} B_{1} B_{1} C_{1} C_{1} D_{1} D_{1} E_{0} E_{3}, A_{1}$ at 3 o'clock, $E_{0}$ at 6 o'clock, $\mathrm{E}_{3}$ at 120 o'clock.

Figs. 5-8.-Metaphases of chilled endosperms.

Fig. 5.-Centric D-fragment (at 9 o'clock), two fragment chromosomes.

FIG. 6.-Isochromosome involving the short arm of a B-chromosome (at 50 'clock).

Fig. 7.-E-chromosome with chromatid break (at in o'clock).

Frg. 8. - Normal metaphase of the cross $\mathrm{C}_{1} \mathrm{C}_{2} \times \mathrm{C}_{1} \mathrm{C}_{1}$. Chromosome complement $\mathrm{A}_{0} \mathrm{~A}_{0} \mathrm{~A}_{0}$ $\mathrm{B}_{1} \mathrm{~B}_{1} \mathrm{~B}_{1} \mathrm{C}_{1} \mathrm{C}_{2} \mathrm{C}_{2} \mathrm{D}_{1} \mathrm{D}_{1} \mathrm{D}_{1} \mathrm{E}_{2} \mathrm{E}_{2} \mathrm{E}_{2}$.

with an $\mathrm{E}_{2}$-, the other with an $\mathrm{E}_{3}$-chromosome (plate, fig. 2). One of the two plants (with the complement $\mathrm{E}_{1}{ }^{3} \mathrm{E}_{2}$ ) was cross-pollinated by an $\mathrm{E}_{2} \mathrm{E}_{2}$-plant. Two endosperms developed with the chromosome combination $\mathrm{E}_{1}{ }^{3} \mathrm{E}_{1}{ }^{3} \mathrm{E}_{2}$ (pre-reductions). In both cases the $\mathrm{E}_{1}{ }^{3}$ chromosome was transmitted unchanged (fig. 4 d).

\section{(c) Spontaneous chromosome breakage}

The subdivision of the cold-treated Trillium chromosomes into euchromatic and $\mathrm{H}$-segments permits us to recognise morphological changes, e.g. losses and gains of euchromatic and heterochromatic substance, relatively easily. At the beginning of our investigations it was already clear that the chromosomes do not always retain their individuality in the course of endosperm development (Rutishauser, 1955a). Centric and acentric fragments, dicentric chromosomes, translocations and rings appear here and there in the mitoses, without an external cause being apparent. To a certain extent they resemble 


\section{s}

$E^{5}$

D.

\section{th}

$B^{4}$

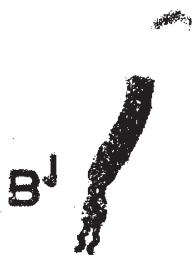

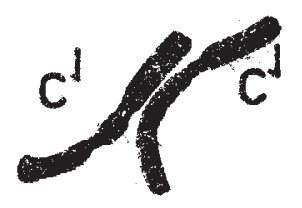

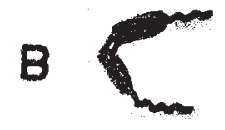

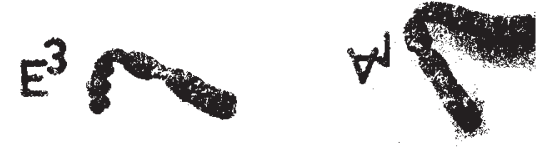
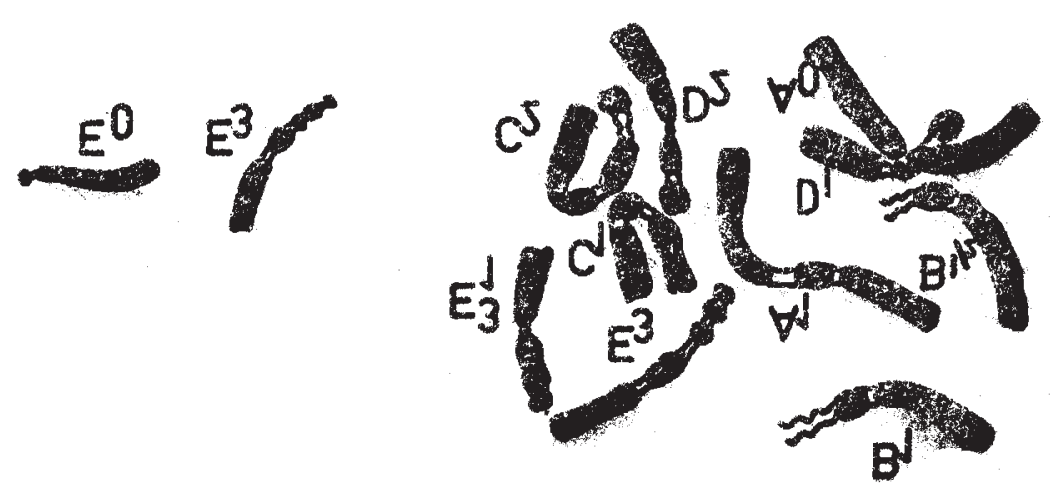

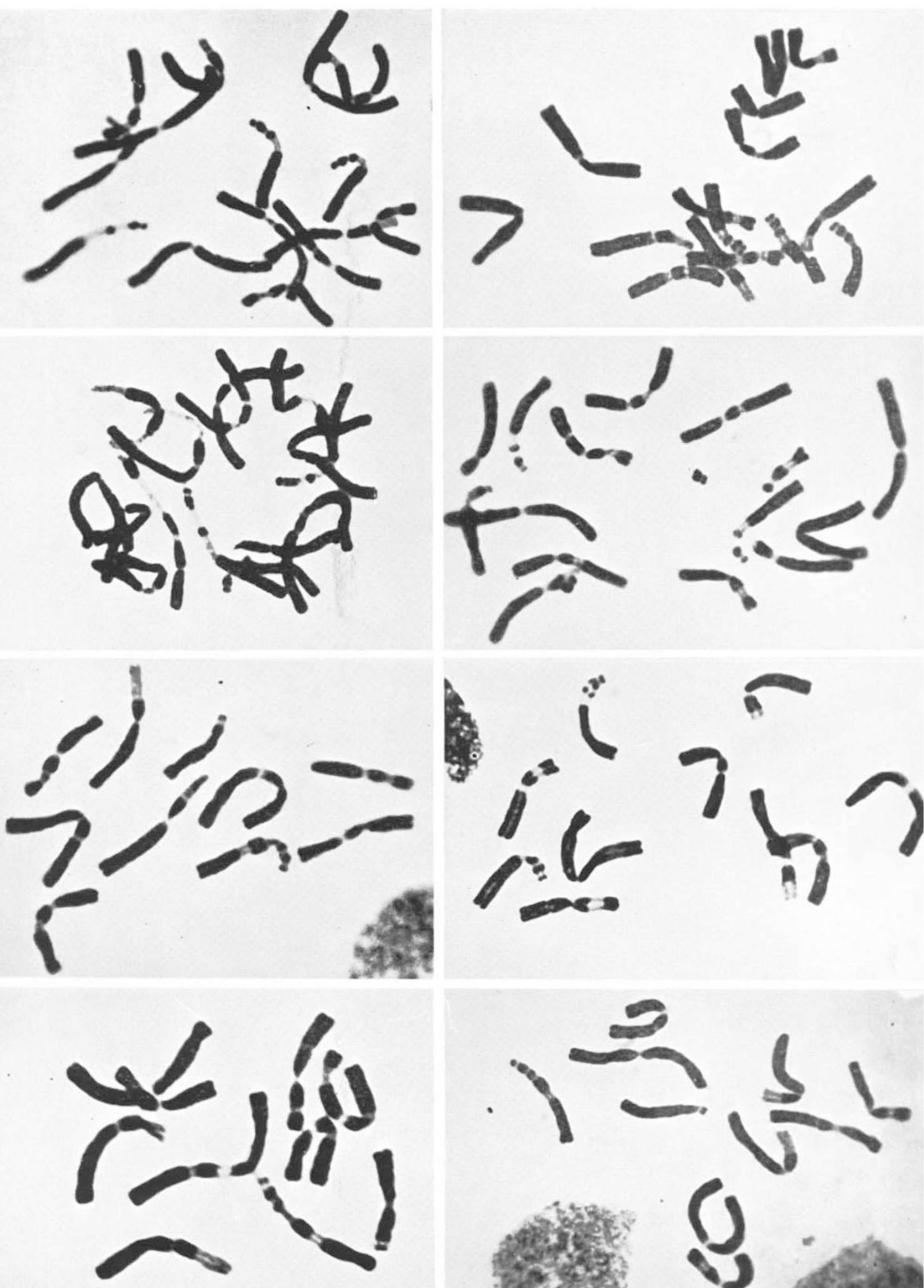
the chromosome fragments which have suffered chromosome breakage by the influence of mutagenic agents.

Types of aberrant chromosomes. In fig. 7 the most frequent types

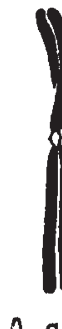

A a

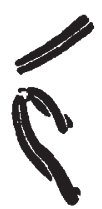

b

B

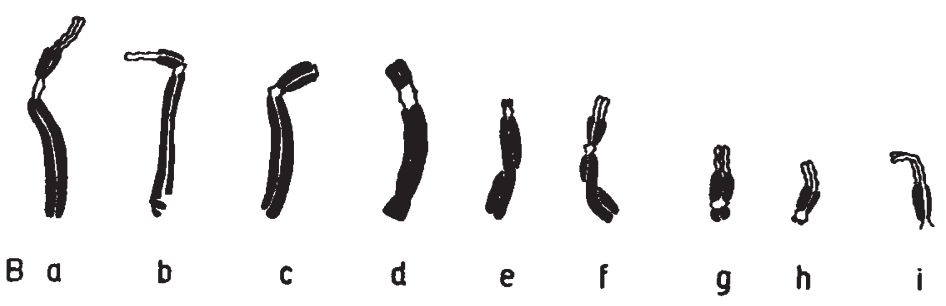

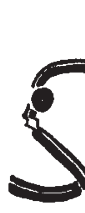

C

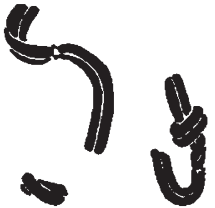

d

e

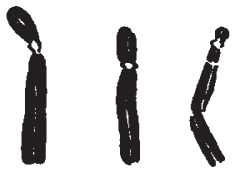

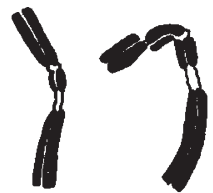

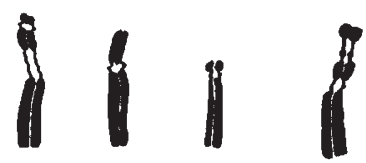

C a

b

c d e
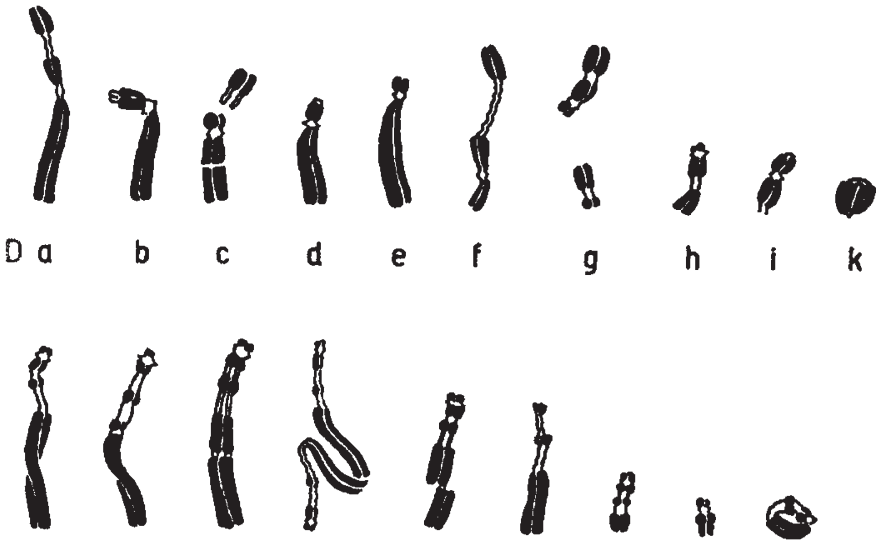

Ea

FIG. 7.-Types of centric and acentric fragments of $T$. grandiflorum (see text). $\times$ rooo.

of aberrant chromosomes are reproduced. For comparison a normal chromosome is shown also (fig. $7 \mathrm{~A}, a-\mathrm{E}, a$ ). It is clear that morphological changes can more easily be seen in such chromosomes as are 
divided into many segments because of the arrangement of the heterochromatin. The E-chromosome is the best to analyse, the A-chromosome the worst.

By far the greatest number of aberrant chromosomes are centric fragments (plate, fig. 5). The breaks are found in the heterochromatin as well as in the euchromatin : any region is breakable. Of particular interest is the discovery that all chromosomes with the exception of the $\mathrm{E}$-chromosome break at or in the centromere and give rise to the development of telocentrics (fig. 7 B, $i$, fig. 8c). As in X-ray-mitoses acentric fragments also appear beside centric fragments, and the fact that they belong to certain chromosomes is often easy to establish (fig. 7 , fig. 8e). Dicentric chromosomes also appear in the mitoses. They come about in three different ways, viz. :

(I) by translocation between non-homologous chromosomes,

(2) by translocations between homologous chromosomes,

(3) by sister reunion (SR).

Dicentric chromosomes of type (I) are the most frequent. All chromosomes can be concerned in them (fig. $8 f, \mathrm{I} o b)$. Dicentric chromosomes which arise through SR, could only twice be observed in E-chromosomes (fig. $7 \mathrm{E}, d, 8 d$ ).

SR apparently occurs only very rarely (fig. 7 A, $f$ ). Until now I have found only four dicentric chromosomes of type (2), three of which belong to the B- and one to the E-chromosome. Of particular interest is the aberrant B-chromosome in plate, fig. 6. It has only one centromere with two identical arms, and so has the appearance of an isochromosome. As it appeared with two B-chromosomes it is probable that it arose from a telocentric chromosome.

Translocations do not of necessity lead to the formation of dicentric chromosomes. Not infrequently centric and acentric fragments of different parentage unite too. But it is only rarely possible to conclude from the form of the changed chromosomes what the derivation of the acentric fragment is which has participated in the translocation.

Monocentric rings were observed only 5 times. Two of them were formed from the A-chromosome (fig. 8a), one each from a B-, D(fig. $7 \mathrm{D}, k$ ) and E-chromosome (fig. $7 \mathrm{E}, i$ ). Acentric rings were somewhat more frequent. All 19 observed rings of this type contained only euchromatin (fig. $7 \mathrm{~A}, c, e$ ).

Centric fragments represent the vast majority of all chromosome aberrations. But rarely fragmentations of chromatids can be observed as well. Some of them are reproduced in fig. $7 \mathrm{~B}, b, \mathrm{E}, e$ and plate, fig. 7. Corresponding to their small number, the frequency of reunions between broken chromatids is extremely small; only two doubtful cases were found.

Initial and secondary breakage. In reference to X-ray treatment, and depending on the time lapse, chromosome breakage of quite a different kind can appear (La Cour, 1952). Metaphases which 
follow directly upon $\mathrm{X}$-ray treatment ( $\mathrm{X}_{1}$ divisions) contain centric and acentric fragments, and also the bridges which are formed in

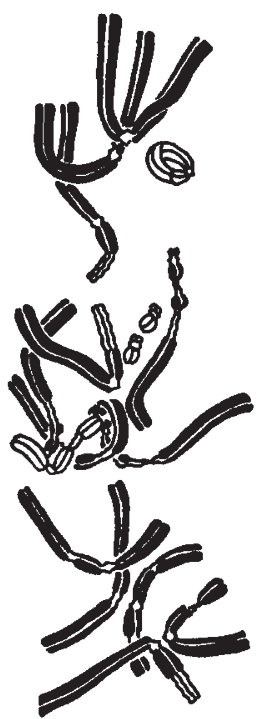

a

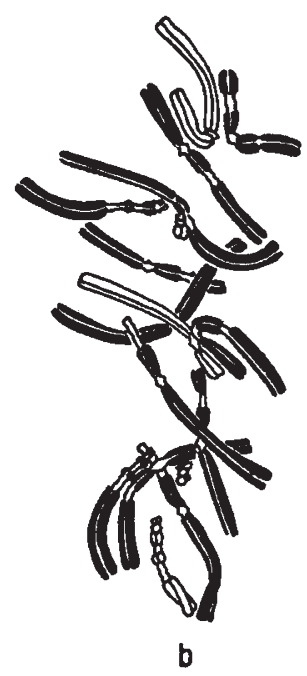<smiles>C=[Ge]</smiles>
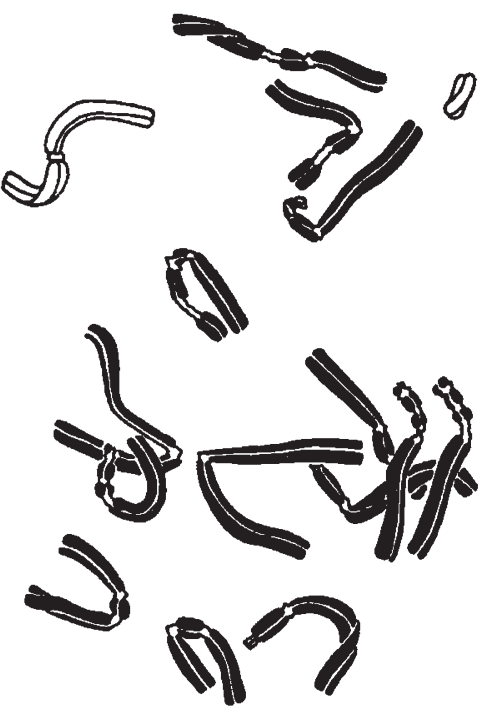

e
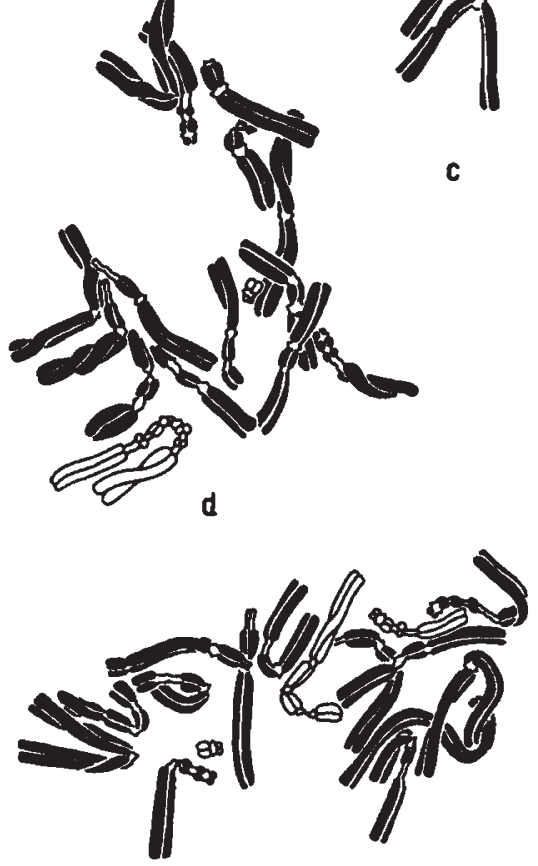

f

Fig. 8.-Metaphases of chilled endosperms. Spontaneous chromosome breakage (black : normal chromosomes, white : broken chromosomes and fragment chromosomes $=\mathrm{fr}$ ). (a) ring of A-chromosome, centric D-fragment, $2 \mathrm{fr}$; (b) centric A-, B- and E-fragment, $2 \mathrm{fr} ;(c)$ telocentric C-chromosome, aberrant $\mathrm{E}_{3}$-chromosome, $3 \mathrm{fr} ;(d)$ dicentric E-chromosome, I fr ; $(e)$ centric and acentric A-fragments ; $(f)$ centric E-fragment, D-chromosome with attached acentric fragment of E-chromosome, I fr. $\times$ Iooo.

the anaphases are accompanied by acentric fragments. As the latter have no centromeres, they are mostly eliminated and form micro- 
nuclei in the telophase or are dissolved. The centric fragments can undergo SR and build bridges in the anaphases. The bridges usually break in two. So more chromosome breakages occur, but this time because of the forces the chromosomes are exposed to in the anaphase, and no longer under the immediate influence of ionising rays. In this process no acentric fragments develop. In the following metaphases and anaphases ( $\mathrm{X}_{2}$ divisions) therefore, as a rule only centric fragments appear.

By far the greatest number of all aberrant chromosomes of $T$. grandiflorum are unaccompanied by acentric fragments. It follows that we are dealing with fragments which were broken in a previous division. Only in a few mitoses could centric and acentric chromosomes side by side be discovered which derive from the same chromosome. In most cases it is a question of fragments of chromosomes, rarely of chromatids. The discovery that most reunions represent dicentric chromosomes which arose through translocation of nonhomologous chromosomes also points to the greater frequency of chromosome breakage. So it is probable that the spontaneous chromosome breakage takes place before the division of the chromosomes during the interkinesis. Signs of subchromatid breakage (La Cour and Rutishauser, 1954) have not yet been found in these investigations.

The distribution of aberrant chromosomes. Most centric fragments occurring in endosperms of $T$. grandiflorum only appear in one metaphase plate. As there were frequently only a few nuclei of the same endosperm in division, which could be analysed, it cannot be stated when most aberrant chromosomes are formed and how often they are reproduced. In some cases, however, a more detailed analysis was possible.

As McClintock (1942a, b), Darlington and Wylie (1952), Hair (1952) and others have shown, the reproduction of centric fragments is often connected with a change of size if SR and bridge-formation preceded division, the secondary breakages do not always take place at the same point in the intercentric arm, and so unequal chromatids are distributed. According to McClintock (1939) the breakage-fusionbridge cycle or SR-cycle only takes place in female gametophytes and in the endosperm. In most embryos, however, the broken ends " heal" and the centric fragments are passed on unchanged.

Another distribution procedure, called the $\mathrm{R}^{\prime \prime}$-cycle by Darlington and Wylie (1952) takes place in maize (McClintock, I942a,b) as well as in $\mathcal{N}$ arcissus. It concerns the division of dicentric chromosomes. If the intercentric arms in criss-cross position break, the broken ends of both chromatids can unite and form a new dicentric chromosome again. This process is the rule with $\mathcal{N a r c i s s u s}$ and the dicentric chromosome of this plant is therefore permanent.

The endosperms of $T$. grandiflorum seem to differ essentially from Zea mays in so far as the distribution of the centric fragments is concerned. $\mathrm{SR}$ is seldom seen in metaphases and anaphases; the 
centric chromosomes therefore divide without bridge building (fig. Io $c$ ). As Brock (1955) supposed for Hyacinthus, McClintock's breakagefusion-bridge cycle is not compulsory for all endosperms. Probably there is in the endosperm also a "healing" against SR. It may well be taken into account therefore that the centric fragments, at least in part, are transmitted unaltered. In good agreement with this supposition is the discovery that the same aberrant chromosome often appears in several metaphase plates of the same endosperm. Many of them, especially these which are derived from B- and Echromosomes, could be found in 6 to 9 mitoses, which proves that they have survived at least 3-4 division cycles unaltered.

Dicentric chromosomes appear only very rarely in more than one metaphase plate. They form bridges, as is seen in the few anaphases with such chromosomes. They are divided parallel only very rarely. However, a dicentric D-chromosome which is presumably transmitted by a male gamete forms an exception. As can be seen from fig. 9
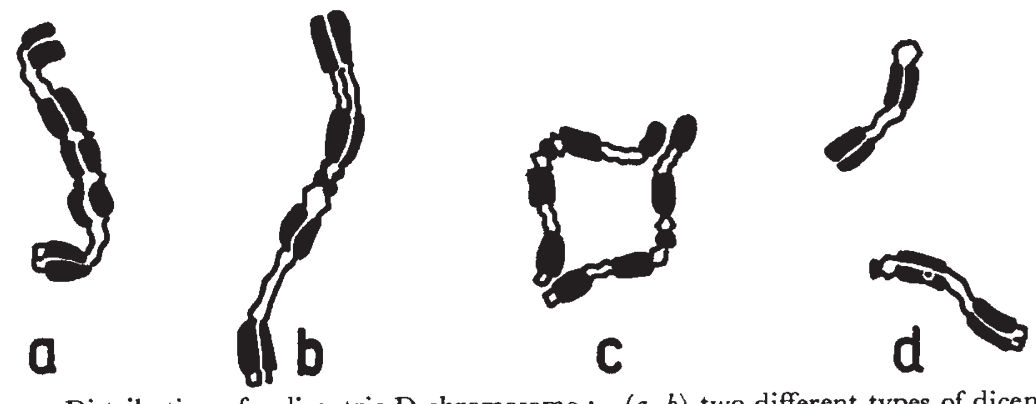

FIG. 9.-Distribution of a dicentric D-chromosome :- $(a, b)$ two different types of dicentric D-chromosomes; (c) anaphase, parallel separation of the dicentric; $(d)$ the two centric fragments of a broken dicentric. $\times 2000$.

the two centromeres lie close to each other, as in the dicentric chromosomes of Scilla peruviana (Battaglia, I 949). They were found in 6 metaphase plates and so have been transmitted through at least 3 division cycles unaltered. The distribution of the dicentric chromatids is mainly parallel (fig. 9). Occasionally bridges may be formed which break in the intercentric arm, often near one centromere (fig. $9 d$ ).

As just mentioned, occasionally broken chromosomes also are carried over into the endosperm by the pollen. The breakages which produced them are here denoted gametic breakages to distinguish them from the somatic ones. The chromosome fragments which appear in all analysable mitoses of an endosperm are considered as gametic in origin. This occurrence is very rare. Among 7 I 7 endosperms only 5 contained gametic breakages, viz. I B and ${ }_{4} \mathrm{D}$ fragments. So only 0.7 per cent. at the most of all gametes have transmitted aberrant chromosomes. This figure is somewhat lower than should be expected from Sparrow's (1950) statements on the number of acentric fragments for microspores of $T$. erectum. 
Frequency of chromosome breakage. Counts of over 2000 mitoses distributed throughout 717 endosperms have disclosed that 355 of 33,354 chromosomes showed breakage. A number of them, about $70-80$, are demonstrably copies of the same broken chromosome. All
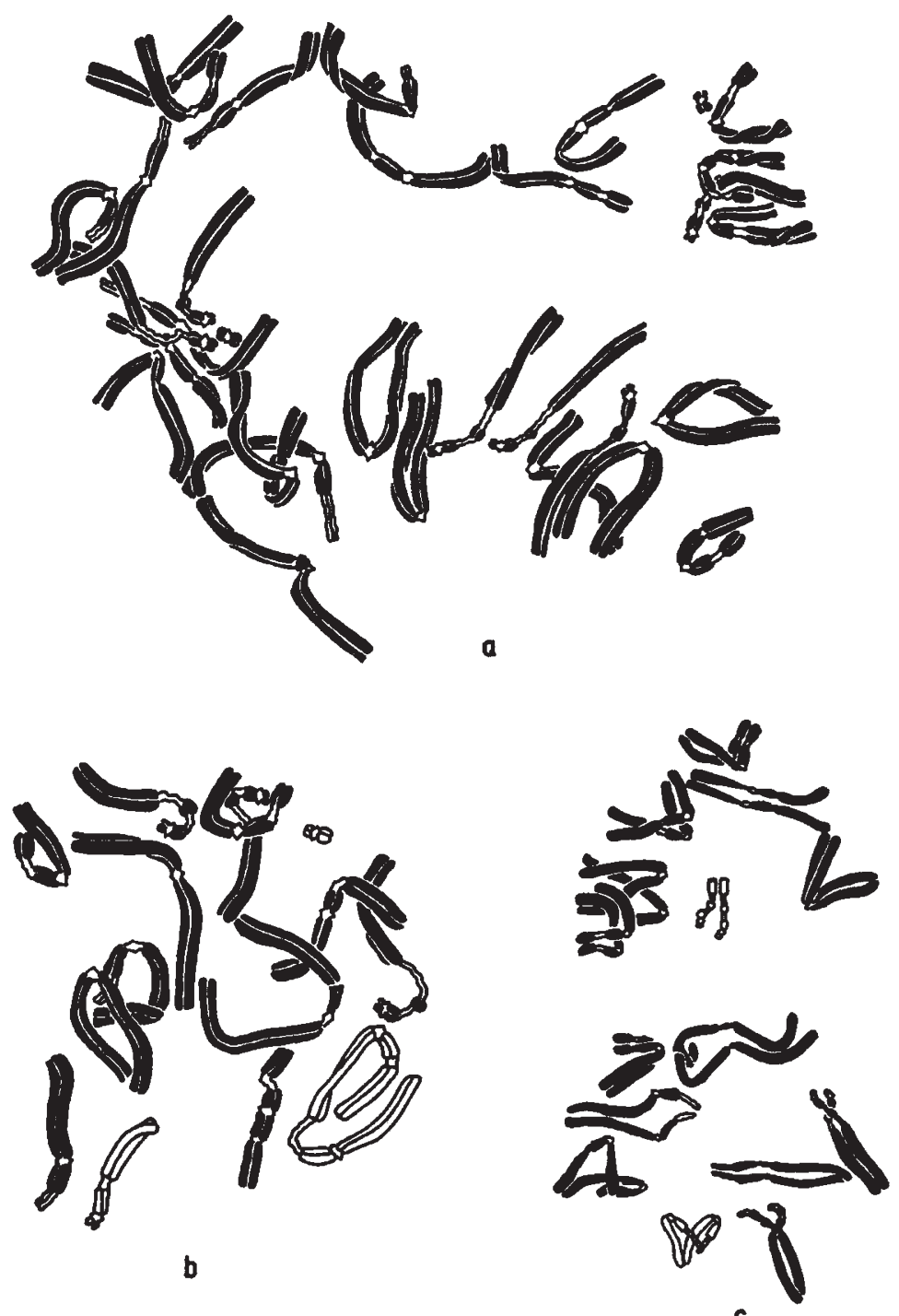

Fig. 10.-Metaphases and anaphase of chilled endosperms (black : normal chromosomes, white : broken chromosomes and fragment chromosomes) :- (a) hexaploid metaphase (note : all chromosomes are normal, $2 \mathrm{fr}$ ) ; $(b)$ centric C-fragment, translocation between B- and C-chromosome, $\mathrm{I} \mathrm{fr} ;(c)$ anaphase, normal distribution of centric B- and E-fragments (no SR). $\times 1000$.

the others appear only once in the same endosperm. Therefore they can be taken as proof that at least one initial breakage has taken place. In order to ascertain the number of initial breakages in endosperms which show copies of centric fragments, the number of 

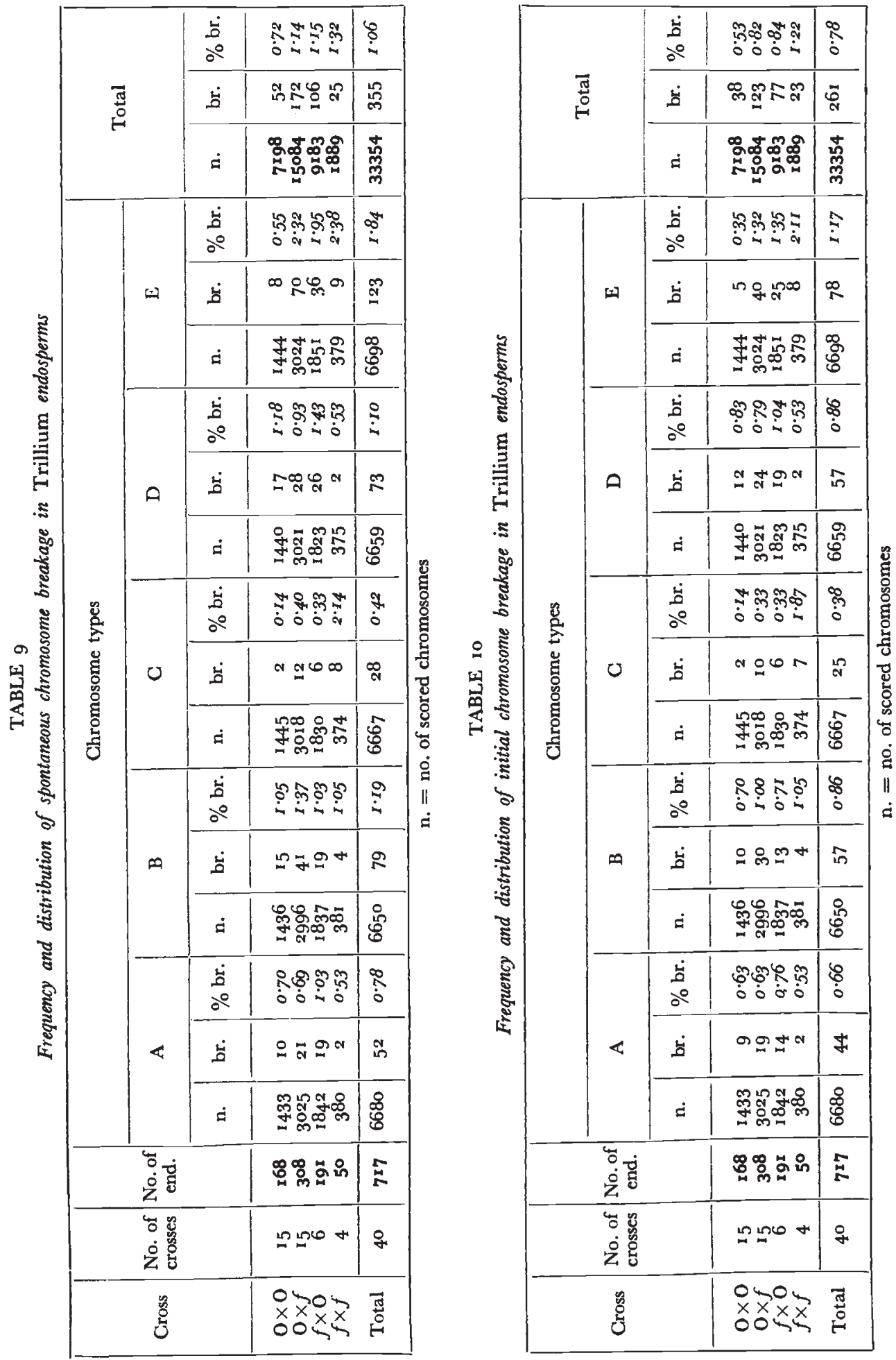
all identical aberrant chromosomes in each endosperm was reduced to one. In table 9 the frequency of all centric fragments including copies is given, and in table Io the frequency of initial breakage. It is possible that the values for initial breakage are a little too high. Occasionally there were found in the same endosperm centric fragments of the same chromosome which differed from each other morphologically. As it cannot be decided for certain whether they arose from secondary changes, e.g. through asymmetric breakage of bridges or whether they should be regarded as signs of two different initial breakages, there is here some source of uncertainty.

With this reservation in mind we can make the following conclusion from the results obtained.

DISTRIBUTION OF BREAKAGE IN TRILLIUM-CHROMOSOMES

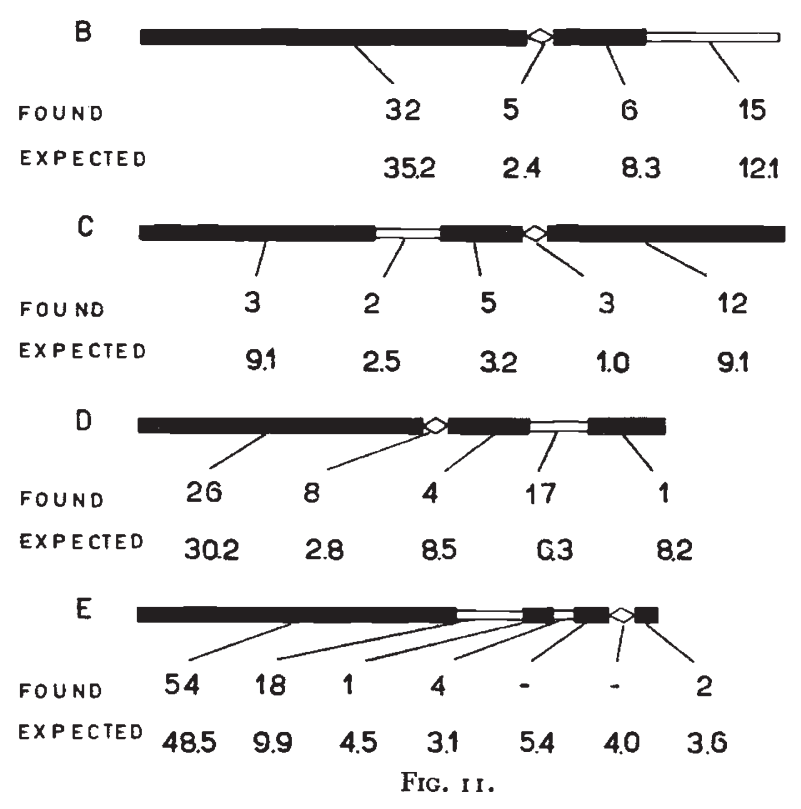

(I) As a comparison of the relative breakage frequencies shows, as presented in tables 9 and $\mathrm{r}$, the corresponding values do not decline uniformly for all chromosomes. The difference amounts to 28 to 34 per cent. for the B- and E-chromosomes, and only about Io to 22 per cent. for the others. That means that the centric fragments of B- and E-chromosomes are reproduced unchanged more frequently than those of the other chromosomes. The A- and Cfragments especially produced only a few copies. It must be noticed that the B- and E-chromosomes are strongly asymmetrical in respect of the position of the centromere. The fragments most often reproduced as a rule developed from a break in the long arm, which led to the formation of short chromosomes with a more median centromere position. It is conceivable that the reproductive ability of the 
fragments is improved thereby. In this sense the position of the centromere seems to have an influence on the multiplication of centric fragments. It would also be possible for the centromere to prevent $\mathrm{SR}$ and so favour the development of copies.

(2) The breaks are unevenly distributed over the 5 chromosomes of the genome of $T$. grandiflorum. The E-chromosome is the most frequently broken, the C-chromosome least. Both synopses give the same picture, but with the difference that the results for initial breakages are somewhat more even. This discovery is reminiscent of the results obtained with radiomimetic substances (Ford, r948; Revell, I952; McLeish, I952) where in contrast with the X-ray experiments, an uneven distribution of breaks in the various chromosomes was observed. In the Trillium experiments, however, the frequency of breakage has no relation either to the absolute length of the chromosomes or to their relative heterochromatin content.

(3) The distribution of breaks over the various regions of the B-, C- and E-chromosomes seems to be more or less random (fig. I I). Only the heterochromatic region of the D-chromosome is favoured for breakage. But it is not improbable that this uneven distribution comes to pass because of secondary changes.

In the experiments on the variability of chromosomes in the course of endosperm development three series of cross tests were included which were carried out on plants with fragment chromosomes. In tables 9 and io the four cross combinations $\mathrm{O} \times \mathrm{O}, \mathrm{O} \times f r, f r \times \mathrm{O}$ and $f r \times f r$ are given separately. It can be seen from the last column of the tables that the number of breaks varies according to the cross combination. It is smallest in the $\mathrm{O} \times \mathrm{O}$ crosses, greatest in the $f r \times f r$ crosses. This discovery gives the impression that there is a connection between frequency of breakage and number of fragment chromosomes. But in all three crosses in which $f r$-plants were included, there were endosperms with and without fragment chromosomes. In the $\mathrm{O} \times f r$ cross there were some endosperms with one fragment chromosome and some without any in the ratio $\mathrm{I}: \mathrm{I}$; in the remaining crosses endosperms appeared with o, I, 2 and 3 standard fragments. So it has proved necessary to calculate the number of centric fragments separately for all endosperm categories.

That has been done in table I I for all broken chromosomes, in table 12 for the initial breaks. From them the following results may be derived: the breakage frequency in the endosperms without fragment chromosomes amounts to $0 \cdot 80$ per cent., rises to $\mathrm{I} \cdot 30$ per cent. in the endosperms with one fragment and remains at about this figure if more standard fragments are introduced.

Table I 2, which gives the distribution of initial breakages, shows the same regularity. In this synopsis also the differences are significant in respect to the breakage frequency of the different endosperm categories $(\mathrm{P}<\mathrm{O} \cdot 00 \mathrm{I})$. The $3 f r$-endosperm, for which too few counts have been made is again an exception. 
A. RUTISHAUSER
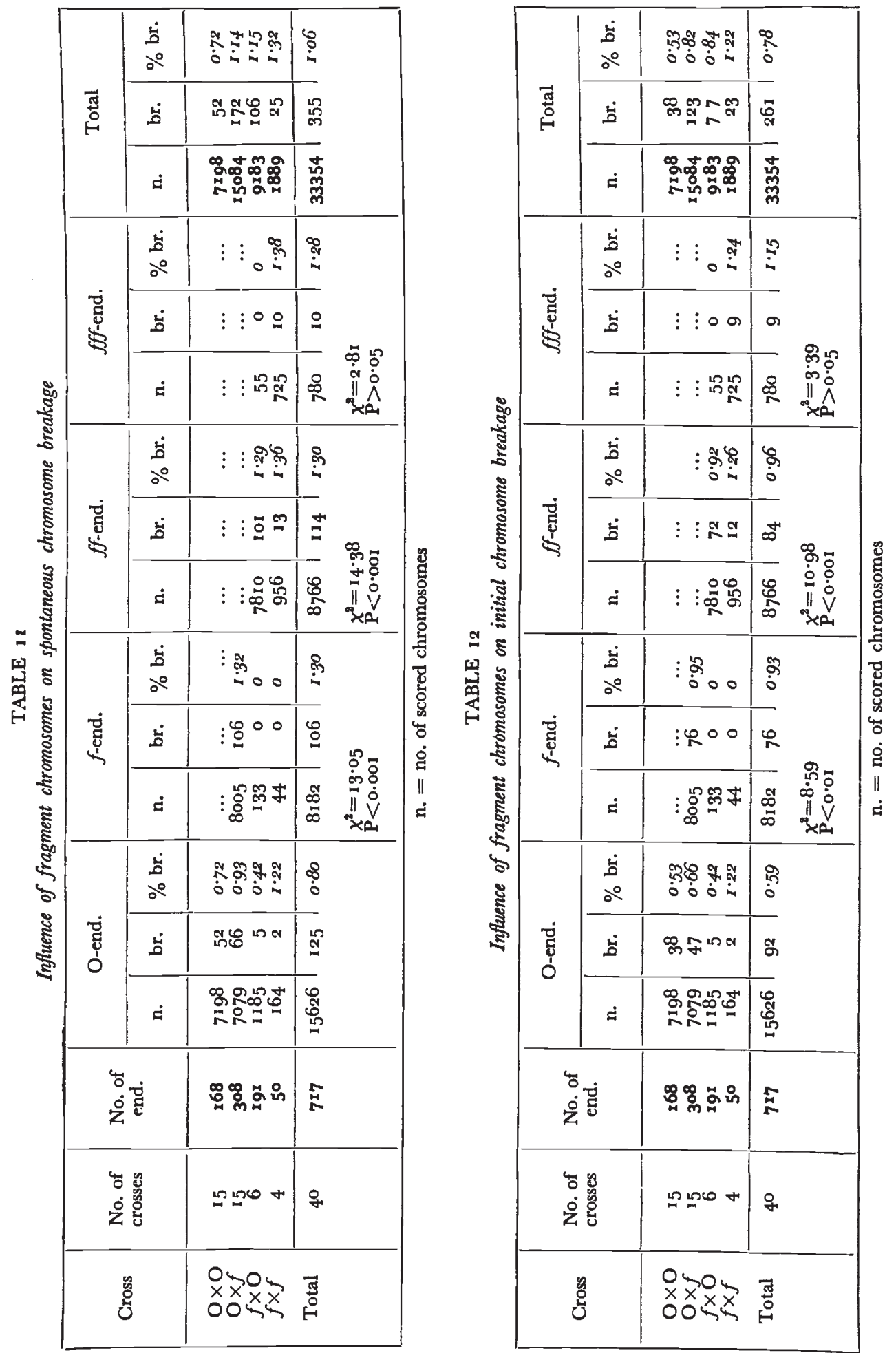
The distribution of breaks over the 2207 analysed mitoses was only ascertained for 349 aberrant chromosomes. The remaining 6 centric fragments lay in mitoses which could not be fully investigated. Further, because of gametic and somatic non-disjunction, the number of investigated mitoses is somewhat lower than would be expected from the total number of chromosomes $(33,354)$. As table I 3 and fig. I 2 show, the distribution of the aberrant chromosomes deviates only slightly from a Poisson distribution, from which it follows that

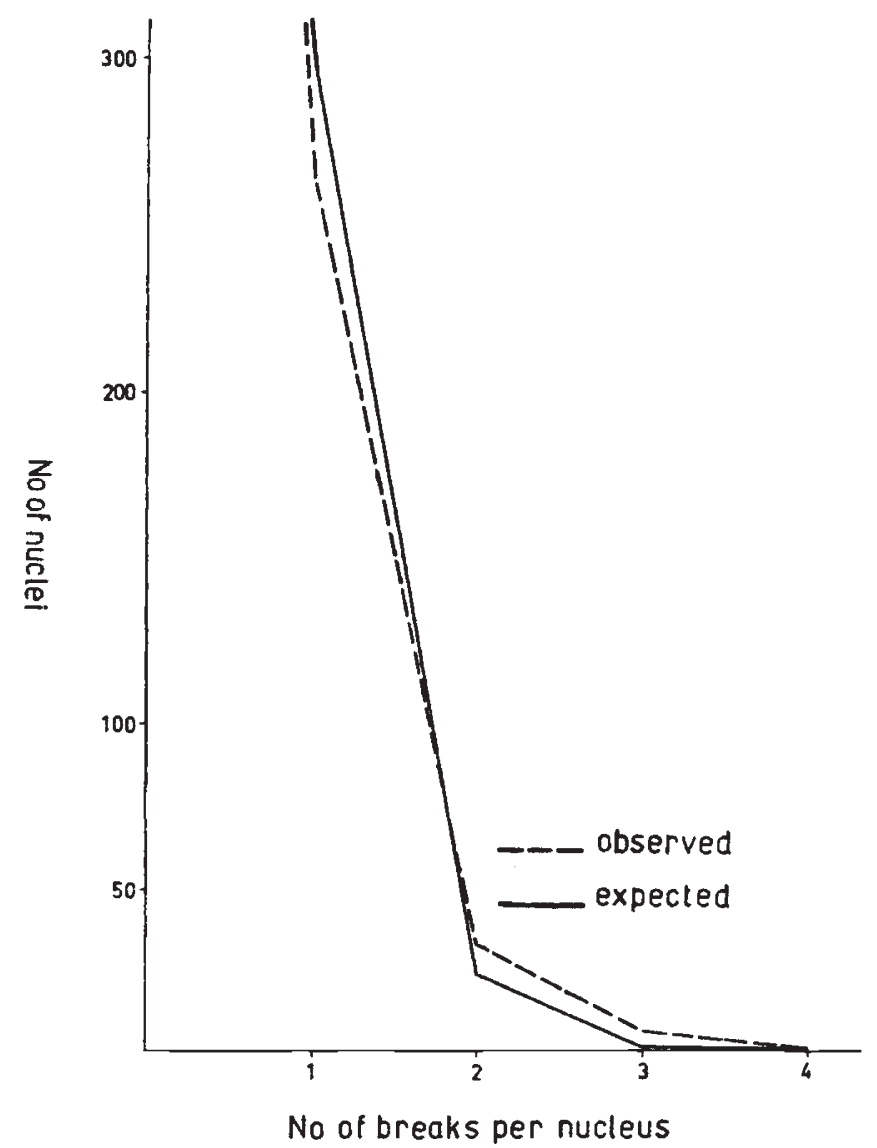

FIG. 12.-Frequency polygon of spontaneous breakage in $T$. grandiflorum.

the number of chromosome breaks is not raised essentially by previous breakages. Unlike Brock (1954) we can therefore find no indications of a snowball increase of breakage frequency.

From the figures presented in table I 3 the frequency of aberrant chromosomes per metaphase amounts to $0 \cdot 15^{8}$. This figure is somewhat smaller than the total frequency of $B^{\prime \prime}$ and $B^{\prime}$ breaks of Trillium roots given an X-ray dose of $5^{r}$ as discovered by Darlington and La Cour (I945). In proportion to the frequency of spontaneous chromosome breakage in other plant organisms, however, it is 
relatively high. So Giles (1940) found in microspores of $T$. canaliculata and $T$. paludosa frequencies of only 0.04 and 0.06 per cent. T. erectum on the other hand, according to Sparrow (1950) shows higher values also in PMC and microspores. But there the breaks which occur during the meiosis are not separated from those which occur during the first pollen grain mitoses. In root cells spontaneous chromosome breakage was only rarely found.

TABLE 13

Frequencies of breaks per nucleus

\begin{tabular}{|c|c|c|}
\hline Classes & Observed & Expected \\
\hline \multirow[t]{2}{*}{$\begin{array}{c}0 \\
1 \\
2 \\
3 / 4\end{array}$} & $\begin{array}{r}\mathrm{r} 905 \\
263 \\
32 \\
7\end{array}$ & $\begin{array}{r}r 884 \cdot 5 \\
297 \cdot 9 \\
23 \cdot 5 \\
1 \cdot 2\end{array}$ \\
\hline & 2207 & $2207 \cdot 1$ \\
\hline \multicolumn{3}{|c|}{$\begin{aligned} \text { Variance } & =0.184 & & \text { Mean }=0.158 \\
\chi^{2} & =35.44 & & P<0.001\end{aligned}$} \\
\hline
\end{tabular}

\section{DISCUSSION}

(i) Heterochromatin in the endosperm

The cold-treatment experiments with the endosperm give further confirmation that the heterochromatin is influenced by the function of the cell as has been found in X-chromosomes of locusts. This is shown particularly clearly in prophase chromosomes of cold-treated plants. In the root-tips the $\mathbf{H}$-segments are only slightly narrower than the euchromatic blocks during the prophase. But in the endosperms they appear as long, thin threads, in contrast with the broad euchromatic segments. Not until prometaphase are the H-segments thickened. So they are clearly late in coiling. The difference between root meristems and endosperms is presumably to be only quantitative. The cold-treated endosperms reveal only one property of the $\mathrm{H}$ segments more clearly. They show that the $\mathrm{H}$-segments are allocyclic in respect not only to their reaction to leuco-basic fuchsin, but also to spiralisation. In the resting nucleus the heterochromatin is strongly spiralised, the euchromatin weakly. The uncoiling of the H-segments, however, appears to be faster and more complete after cold-treatment. Further, the heterochromatin lags in respect to formation of a new spiral (see also Boothroyd, 1953).

The cold-treatment also has an influence on the reaction of the $\mathrm{H}$-segments to Feulgen staining. The uncoiled heterochromatic prophase threads appear more lightly stained than the euchromatin. It is debatable whether this difference is due to the weaker staining intensity or whether it only appears so because of the smaller diameter 
of the threads. Later, with increased spiralisation and shortening of the H-segments this uncertainty disappears. The reaction to Feulgen is then clearly negative or at least weakened in relation to the euchromatic regions.

The results given refer to the behaviour of the heterochromatin in the micropylar part of the endosperm only. In the chalazal region it is somewhat different. The endosperm nuclei of this section are always more darkly stained, as are the chromosomes of all mitoses stages. The cold effect manifests itself only incompletely. The difference in staining between euchromatin and heterochromatin is smaller in the metaphase stage, and particularly, the prophase chromosomes show no uncoiled regions. Euchromatin and heterochromatin are not distinguishable during the prophase, and in the metaphase plates the differences are blurred. From these observations it follows that the $\mathrm{H}$-segments of the same plant, even of the same tissue, react differently to low temperatures.

The difference in the staining ability of micropylar and chalazal endosperm nuclei is parallel to a difference in cold effect. The $\mathrm{H}$-segments are weaker stained in mitoses which derive from weakly stained nuclei, and the same is true for euchromatin also. If we take the staining intensity with leuco-basic fuchsin as an index of the deoxyribosenucleic acid (DNA) content it appears that the cold effect is not produced when originally there is much DNA present. This interpretation would agree with Darlington's conception, according to which heterochromatic regions are only revealed when the supply of DNA drops below a threshold value.

The more recent interpretation of DNA as an active genetic substance makes an exchange of DNA with different genetically active and inactive regions of the chromosome improbable. The assumption that the production of DNA is lowered by cold-treatment, whereby the H-segments react more sensitively to the changed environment is then more likely. The peripheral position of the chromocentres would also support such an interpretation (Vanderlyn, I949). Or we have to assume with Darlington (I955) that there are different states of DNA.

\section{(ii) Cytological evidence of crossing-over}

The consequences of crossing-over can only be cytologically examined when the partners of a homologous chromosome pair are different. Deficiencies can serve as a landmark, or the normally present morphological differences between $\mathrm{X}$ - and Y-chromosomes can be used (Koller and Darlington, I934; Matthey, I936, but see also Matthey, I952). Further, for such examinations the condition must be fulfilled that the two chromatids which come from the first meiotic division remain together or if they were divided, unite again.

The second condition is fulfilled if the division products of heteromorphic bivalents can be distinguished from one another clearly in 
the anaphase of the first meiotic division. Such examinations have been carried out by Carothers (1913), Wenrich (1916), Darlington (1936), White (1949) and others, with locusts, and by Hearne and Huskins (1935) with Melanoplus femur-rubrum and Huskins and Spier (1934) with Triticum vulgare.

Three modes of behaviour of heteromorphic bivalents can be found : the first meiotic division is either purely reductional or purely equational or it is a mixture of both division types. That would mean that between the centromere and the point where the difference begins either a chiasma is formed always or never, or that finally chiasmata sometimes appear and sometimes not.

The reason for the different meiotic behaviour of heteromorphic bivalents depends on their structure, according to Mather (1935) and Darlington (1937). If the difference lies close to the centromere, no chiasma is formed proximal to it, the division is always reductional (pre-reduction). If the difference lies on the opposite end, and if only one chiasma is formed, the bivalents split equationally (postreduction). So it is the position of the difference, or rather its distance from the centromere which determines the mode of reduction.

With plants of the Allium type of embryo-sac development it is possible to examine the cytological consequences of crossing-over in the endosperm. The two chromatids of a dyad are separated in the course of embryo-sac development. They are distributed to the two nuclei of the two-nuclear embryo-sac, each of which forms a quartet of haploid nuclei. Later two nuclei of the two quartets fuse together and thereby the two chromatids are brought together again.

A similar procedure has already been used by Goldschmidt (1932) to discover whether post- or pre-reduction takes place. In Bombyx mori the second polar body is occasionally not ejected, but remains in the egg and like the egg nucleus is fertilised by a sperm nucleus. If the two nuclei are different, mosaics appear. Gynandromorphs, for example, are formed when the X- Y-chromosome pair split equationally. In this case too, it is assumed that the values obtained for the frequency of pre-reductions depend on the distance between the difference and the centromere.

The cytological analysis of the endosperm from crosses of plants with heteromorphic chromosome pairs makes possible further statements about the mechanism of crossing-over. In these examinations only chromosomes which differed in number and position of heterochromatic blocks took part. The euchromatic regions of the heteromorphic chromosome pairs are always equally long. As cross experiments of the type $\mathrm{C}_{1} \mathrm{C}_{1} \times \mathrm{C}_{1} \mathrm{C}_{2}$ show, the difference in heterochromatin content has a physiological effect which must be taken into account in the interpretation of the results : endosperms of the constitution $\mathrm{C}_{1} \mathrm{C}_{1} \mathrm{C}_{1}$ and $\mathrm{C}_{1} \mathrm{C}_{1} \mathrm{C}_{2}$ appear approximately in the ratio $\mathrm{I}: 2$ instead of $I: I$, i.e. either the gametes or the endosperms with $\mathrm{C}_{2}$-chromosomes are favoured. The same effect is also found when $\mathrm{E}_{0^{-}}$and $\mathrm{E}_{3}$-chromo- 
somes compete with one another. In the $\mathrm{E}_{2} \mathrm{E}_{3}$ experiments, however, the effect is lacking.

The frequencies of post-reductions presented in table 5 are correct for the combination $\mathrm{E}_{2} \mathrm{E}_{3} \times \mathrm{E}_{2} \mathrm{E}_{2}$, but they are presumably too great for the combination $\mathrm{C}_{1} \mathrm{C}_{2} \times \mathrm{C}_{1} \mathrm{C}_{1}$ and $\mathrm{C}_{1} \mathrm{C}_{2} \times \mathrm{C}_{1} \mathrm{C}_{2}$, supposing that on the female side, too, gametes or endosperms with $\mathrm{C}_{2}$-chromosomes are favoured. It cannot be stated for certain whether the results of the $B_{1} B_{1 / 4} \times B_{1} B_{1}$ also have been changed by a physiological effect of the heterochromatin. But even when the influence operates in reverse there (favouring the $\mathrm{B}_{1 / \mathrm{s}}$ gametes or endosperms and thereby raising the values for post-reduction) the results of our experiments would still hold: the frequency of post-reduction is not proportionally dependent on the distance between difference and centromere. The highest value coincides with the shortest distance.

Darlington (1937) and Mather (r937) have already shown the disproportion between the size of chromosomes and number of chiasmata. The discrepancy is particularly great where the size difference between the chromosomes is marked, as for example in Stenobothrus parallelus (Darlington and Dark, 1932) and Melanoplus femur-rubrum (Hearne and Huskins, 1935). Darlington and Mather attribute the phenomenon to the fact that the points at which crossingover can occur are localised. Localisation of chiasmata is cytologically proved for Mecostetus, Fritillaria meleagris and other organisms. According to Mather's (1937) view it is, however, general. In his opinion the first chiasma always occupies a definite region of the chromosomes. This region, which is designated "differential distance", lies near a landmark of the chromosome, e.g. the centromere or the distal end of the chromosome. If the chromosome exceeds the length of the differential distance, further chiasmata can be formed at intervals determined by interference.

On the basis of this interpretation of chiasma distribution the results of my experiments can be understood. Assuming that the first chiasma of both chromosome arms always lies near the centromere (proximal localisation) and that because of this the frequency of chiasma formation is greater in this region than at other places in the chromosome, it is understandable why there is no correlation between measured centromere distance and chiasma frequency. If the distance between difference and centromere is short, as in the short arm of the B-chromosome, only one chiasma is formed on this length. The frequency of post-reductions is therefore high. If, with an increased interval, as for example in an E-chromosome, another chiasma appears, the number of post-reductions falls, because then part of the crossover is cancelled by the second chiasma. The greater distance from the centromere must therefore lead first to a decline in the frequency of post-reductions. It does not rise again until more chiasmata are formed.

Unfortunately there are at present no analyses of meiotic divisions 
for $T$. grandiflorum which could be used in comparison with the results obtained with endosperms. According to Huskins and Smith (1935, 1938) the number of chiasmata per nucleus for $T$. erectum is relatively small. It varies between 14.4 and 17.15 according to the phase of division investigated, and may therefore amount to not more than three on the average for each chromosome pair. The chiasmata do not appear to be localised. Proximal localisation of chiasmata, however, has been ascertained for $T$. kamtschaticum by Matsuura (1937). I shall not go into his interpretation of the meiosis of this plant (neo-two-plane theory) until more results of the cross $\mathrm{E}_{0} \mathrm{E}_{3} \times \mathrm{E}_{2} \mathrm{E}_{2}$ are at hand.

From the work of Darlington and La Cour (1941), Kurabayashi (1952) and Haga and Kurabayashi (1954) as well as from my own investigations it is clear that the structure of the Trillium chromosomes is extremely variable. Number, position and length of the heterochromatic regions-and occasionally the euchromatic regions toochange even between individuals of the same population. Haga and Kurabayashi have shown that this variability in the last resort goes back to chromosome breakage and consequent reunions. They succeeded in discovering inversions and translocations in T. kamtschaticum and the results of my own experiments point in the same direction. But they point out yet another source of the diversity of forms : new chromosome types can arise from crossing-over, provided that heteromorphic chromosome pairs are present. So a new $\mathrm{E}_{1^{-}}$ chromosome $\left(E_{1}{ }^{3}\right)$ developed from the homologous chromosome pair $\mathrm{E}_{0} \mathrm{E}_{3}$, the H-segment of which was distal instead of being proximal. All remaining discovered chromosome types (the $\mathrm{E}_{1}{ }^{1}$ - and $\mathrm{E}_{2}$-chromosomes) can be derived from the same heteromorphic chromosome pair by changes in the number and position of the chiasmata.

\section{(iii) Spontaneous chromosome breakage}

Structural changes of chromosomes can appear in different places in the nuclear cycle. According to Darlington's chiasma-type theory chromatid breakages and reunions normally appear during prophase of the first meiotic division. As a rule they only lead to visible structural changes if the homologous chromosomes show inversions following previous breakages. From these chromosome aberrations of structural hybrids we must distinguish sharply the chromosomal changes appearing in the course of mitoses. These alone are termed spontaneous chromosome breakage here.

Isolated references to the appearance of spontaneously developed aberrant chromosomes and their behaviour in the course of development are frequent in literature. But there have been very few experiments which could throw light upon the nature and time of their origin. It seems to be clear from the results to hand that not all tissues are equally subject to the phenomenon of spontaneous chromosome breakage. By far the most breakages have been found in gametophytes, 
especially in pollen grain mitoses (Darlington and Upcott, I94I ; Giles, 1940-4I ; Sparrow and Sparrow, 1950) in embryo-sacs (Haga and Kurabayashi, I954) and also in ovular tissues (Kurabayashi, I952) and recently also in the endosperm (Rutishauser, I953, I954a : Brock, 1953, 1954). On the other hand they are relatively rare in mitoses of root-tips.

With $T$. grandiflorum the experiment was made to determine quantitatively the breakage frequency in the endosperm and in the root tissue. As this species is highly self-sterile, both tissues derive from cross-pollinated seeds. In 2 I 29 chromosomes of root mitoses, including those with fragment chromosomes, not a single aberrant chromosome was found, and in 33,354 chromosomes of endosperms, on the other hand, there were 355 . Thus the breakage frequency differs in these two tissues. Kurabayashi (1952) comes to the same conclusion: in T. kamtschaticum spontaneous chromosome breakages occur occasionally in the ovular tissue (in one plant in 23 per cent. of all cells) but very rarely or never in root-tips. As chromosome breaks are connected with losses or at least with transposition of genetic substances, it is to be assumed that the somatic mutability also is dependent on the tissue. That has already been shown in the case of the endosperm of maize. According to Jones (1936a) the number of seeds with mosaics in ccG-endosperms is more than 25 per cent. $(\mathrm{C}=$ basic factor for colour). The mosaic rate per cell is reckoned at $I: 70,000$. But that of spontaneous gene mutation $\mathrm{c} \rightarrow \mathrm{C}$ in gametes is with $\mathrm{I}:$ I4 millions considerably lower (Jones, $1936 b$ ).

Different suppositions have been made about the cause of the increased appearance of chromosome breakage in many plant tissues. Kurabayashi (1952) attributes the phenomenon to a disturbance of genetic balance. But where the chromosome complement is balanced he supposes a disturbance of the mechanism which is connected with the chromatin increase. Brock (1954) believes that the endosperm, where particularly many spontaneous chromosome breaks occur, reacts more sensitively in relation to other tissues. In my view it is conceivable and even probable that the higher "sensitivity" of the endosperm is only simulated. The higher breakage frequency could come about simply because in the endosperm mutagenic agents are formed or accumulated more easily than elsewhere. The endosperm has a nutritional function, so its metabolism must be different from that of a root-tip cell. The same is also true of the ovular tissue and the tapetum.

The factors which cause chromosome breakage are still unknown. The natural ionising rays are not sufficient for their causation. As a rule a disturbance of genetic balance or of cell metabolism is held responsible. As especially Giles (I940-4I) was able to show with a very large number of samples, the breakage frequency in the pollen grains of hybrid species is higher than in the parents. In the $F_{2}$ hybrids between Tradescantia canaliculata and $T$. humilis it increases 
threefold and is still higher in triploid hybrids between $T$. canaliculata and $T$. paludosa. Giles attributes this increase of spontaneous breakage frequency to a disturbance of the balance of the chromosome complement. He observes mistakes in the coiling cycle and believes that genes which disturb the normal timing of the coiling cycle are accumulated by the cross. Brock too (1955) tries to explain the high breakage frequency in endosperms of hyacinths by disturbances in the balance. The addition of a long chromosome with nucleolus organiser raises the breakage frequency more sharply than when $2 \mathrm{~L}^{n}$ chromosomes are introduced. The decisive investigation, however, has only been carried out on a single endosperm and therefore cannot be accepted as validated.

In another work (Rutishauser and La Cour, 1955) it has been shown that even hybridisation between species of different genera does not always lead to an increase in breakage frequency. The breakage frequency in the endosperms of the cross Paris quadrifolius $\times$ $T$. grandiflorum is twenty times greater than in the endosperms of the reciprocal crosses and in the latter not much higher than in pure Trillium endosperms. So it is not probable that the hybrid constitution or the disturbance of the chromosome balance in itself alters the breakage frequency. Rather would it appear that special conditions must be fulfilled for the induction of spontaneous chromosome breakage.

The experiments with fragment chromosomes point in the same direction. It has been stated above in some detail that the breakage frequency in endosperms with 1,2 , or 3 fragment chromosomes is distinctly higher than in endosperms with none ( $\mathrm{I} \cdot 3$ per cent. as opposed to $0 \cdot 80$ per cent.). This result could also mean of course that a disturbance of the genetic balance is caused by the fragment chromosomes. Fragment chromosomes indeed often have a detrimental effect (cf. Müntzing, I943; Randolph, 1941) and particularly on the seed fertility. In T. grandiflorum this is, however, not the case. The seed setting of crosses between plants without fragment chromosomes is smaller than in crosses between fragment plants (Rutishauser, 1956). A further result is also striking: the effect of the fragment chromosomes is not noticeably cumulative. The breakage frequency is not significantly increased by the introduction of more than one fragment chromosome. This result, too, supports the conclusion that a special influence is exerted by the fragment chromosome and that the spontaneous chromosome breakages in the endosperms of $T$. grandiflorum are genetically controlled.

The assumption that spontaneous chromosome breakages are subjected to a genetic control is supported by the results of experiments on the somatic mutability of maize (Rhoades, 1936, 1938) and of some species of cotton (Harland, I937). In both plant groups genes could be found which significantly raised the mutation rate. The mutator gene of Zea mays $(\mathrm{Dt})$ is in addition active in the endosperm and there 
it influences the mutability of a colour factor. Unlike spontaneous chromosome breakage it is here of course a matter of gene and not chromosome mutation. Rhoades considers it probable that chemical substances are produced by the Dt-gene which raise the mutation rate. The results of my own experiments also lead to a similar view.

Spontaneous chromosome breakages have much in common with chemically induced breakages, as has been pointed out particularly by Gray (1952). According to Revell (1952) the latter differ from breakages produced by ionising rays in that they are concentrated in certain places in the chromosome and that certain chromosomes are affected more readily than others. The Trillium experiments point in the same direction: the distribution of chromosome breaks is not a chance one. The E-chromosome is preferred, and the Cchromosome rarely breaks. The distribution of breaks over the different regions does, however, seems to be more or less haphazard. Only in the D-chromosomes is the heterochromatic region more frequently broken than the euchromatic. More marked is the unevenness of distribution of chromosome breaks in hybrid endosperms of the cross Paris quadrifolius $\times \mathcal{T}$. grandiflorum (Rutishauser and La Cour, 1956). There, for example, in the E-chromosome twelve times as many breaks occur as in the B-chromosome. The view mentioned several times above that the chromosome breaks are caused by a disturbance of the cell metabolism, gains another support by these considerations.

Brock (1954, I955) expounds the view that the seed-fertility is also influenced by errors in division in his work on spontaneous chromosome breakages in the endosperm of lily hybrids and hyacinths. The formation of persisting bridges is regarded as the immediate cause of this. They lead to the development of polyploid nuclei and so to a disturbance of the chromosome balance.

In Trillium endosperms SR and consequently bridges are relatively rare. The centric fragments are usually passed on unchanged. McClintock's breakage-fusion-bridge cycle does not come into action, at least in older endosperms, or else it is not compulsory. Similar observations have been made by Brock himself in connection with hyacinths. With T. grandiflorum also no snowball spreading of chromosome breakages can be shown. It is true that the distribution of breaks over the 2207 analysed mitoses is not a chance one. But the breakage frequency seems to be only slightly influenced by previous chromosome breakages.

Polyploid and spontaneous chromosome breakage do not reduce the seed fertility of $T$. grandiflorum. As already mentioned, the seed setting of the crosses with fragment plants tends to be bigger than that of plants which have none. So it appears that it is at least debatable whether in this species spontaneous chromosome breakage can be regarded as the cause of the reduced seed setting. In a further work it will be shown that the failure of endosperm development in 
Trillium $\times$ Paris hybrids is not connected with an increase in spontaneous breakage frequency.

\section{SUMMARY}

I. The staining of heterochromatic segments (H-segments) in $T$. grandiflorum depends not only on the temperature, but also on the functional condition of the tissue. As a rule weaker stained nuclei reveal weaker stained $\mathrm{H}$-segments. Their coiling processes are also affected.

2. The H-segments of $\mathcal{T}$. grandiflorum are with few exceptions constant in size, number and position in the same individual, but they vary from individual to individual in the same batch of samples. The E-chromosome varies most. The aberrant chromosomes mostly occur in heterozygous combinations, as a rule only standard types are homozygous.

3. The 5 chromosome types are as a rule passed on to the endosperms unchanged. By non-disjunction I per cent. of female and male gametes develop with hyperhaploid and hypohaploid chromosome complements. It is greater on the male than on the female side.

4. The following properties of $T$. grandiflorum permit a cytological investigation of the consequences of crossing-over in the endosperm : (a) the homologous chromosome pairs are occasionally heteromorphic. (b) The two chromatids which are separated in the second meiosis are brought together again in the endosperm, so that it is possible to carry out " tetrad-analyses".

5. The number of post-reductions varies between $5^{6}$ and 84 per cent. for B-, C- and E-chromosomes. The frequency of post-reductions is not proportional to the measured distance between the centromere and the point where the difference begins. This finding is due to the localisation of the chiasmata.

6 . In the endosperms of $T$. grandiflorum centric fragments, rings, dicentric and telocentric chromosomes appear as consequences of spontaneous chromosome breakage with a frequency of $\mathrm{I} \cdot 06 \mathrm{per}$ cent. The frequency of initial breakage is reckoned at $0 \cdot 80$ per cent. The centric fragments are passed on unchanged for the most part.

7. The breakages are distributed unevenly over the 5 Trillium chromosomes. The E-chromosome is most breakable, the C-chromosome least.

8. The frequency of spontaneous chromosome breakage is dependent on tissue. In root cells no aberrant chromosomes are found.

9. Fragment chromosomes (B- or accessory chromosomes) raise the breakage frequency. From this it is concluded that the spontaneous chromosome breakage is controlled genetically.

Io. The development of the endosperm is not influenced unfavourably by spontaneous chromosome breakages. 
Acknowledgment.-This work was carried out with the help of a grant from the Swiss National Fund. I am deeply obliged to the Forschungsrat of the Swiss National Fund as well as to the Regierungsrat of the Schaffhausen canton, for the support they have given my work. I am indebted to Prof. C. D. Darlington, Oxford, and Mr L. F. La Cour for their advice and criticism. Further, I owe my thanks to Miss J. Botta and Miss U. Bringolf for valuable help and Mr A. K. McGill for the translation of the manuscript.

\section{REFERENCES}

BAtTAgliA, E. 1949. Mutazione chromosomiche in Scilla peruviana L. Caryologia, $1,144^{-1} 74$.

воотнRоYD, E. R. 1953. The reaction of Trillium pollen-tube chromosomes to cold treatment during mitosis. 7. Heredity, 44, 2-9.

BROCK, R. D. 1954. Spontaneous chromosome breakage in Lilium endosperm. Ann. of Bot., N.S., 18, 7-14.

BROCK, R. D. 1954. Fertility in Lilium hybrids. Heredity, 8, 409-420.

BROCK, R. D. 1955. Chromosome balance and endosperm failure in Hyacinths. Heredity, 9, 199-222.

CAROTHERs, E. E. 1913. The Mendelian ratio in relation to certain orthopteran chromosomes. F. Morph., 24, 487-511.

CLARK, F. J., AND COPELAND, F. c. 1940. Chromosome aberrations in the endosperm of maize. Amer. J. Bot., 27, 247-25r.

COOPER, D. c. 1933. Nuclear divisions in the tapetal cells of certain angiosperms. Amer. F. Bot., 2o, 358-364.

COUlter, J. M., AND Chamberlain, c. J. 1915. Morphology of Angiosperms, New York.

DARLINGTON, C. D. 1936. Grossing-over and its mechanical relationships in Chorthippus and Stauroderus. 7. Genet., 33, 465-500.

DARLington, c. D. 1937. Recent Advances in Cytology. London, 2nd ed.

Darlington, c. D. 1950. Physical and chemical breakage of chromosomes. Pubbl. Staz. Napoli, Suppl. Vol., 22, 1-11.

DARLINGTON, C. D. 1952. The problem of chromosome breakage : an introduction. Heredity, 6, v-viii.

DARLington, C. D. 1955. The chromosome as a physico-chemical entity. Nature, $176,1139-1144$.

DARLINGTON, C. D., AND DARK, s. o.s. 1932. The origin and behaviour of chiasmata II. Stenobothrus parallelus. Cytologia, 3, 169-185.

DARLINGTON, C. D., AND LA COUR, L. F. 1940. Nucleic acid starvation of chromosomes in Trillium. 7. Genet., 40, 185-213.

DARLINGTON, c. D., AND LA COUR, L. F. 1941. The detection of inert genes. $\mathcal{F}$. Heredity, 32, 115-121.

DARLington, G. D., AND LA COUR, L. F. 1945. Chromosome breakage and the nucleic acid cycle. 7. Genet., 46, 180-267.

DARLINGTON, C. D., AND GaIRDNER, A. E. 1937. The variation system in Campanula persicifolia. 7. Genet., 35, 97-128.

DARLINGTON, C. D., AND UPCOTT, м. B. 1941. Spontaneous chromosome changes. 7. Genet., 4 , 297-338.

DARLINGTON, C. D., AND WYLIE, A. P. 1952. A dicentric cycle in Narcissus. Heredity, $6,197-213$.

ERNST, A. 1902. Chromosomenreduktion, Entwicklung des Embryosacks und Befruchtung bei Paris quadrifolius L. und Trillium grandiflorum Salsb. Flora, $9 I, 1-46$.

FORD, C. E. 1948. Chromosome breakage in nitrogen mustard treated Vicia faba root-tip cells. Proc. 8th Intern. Cong. Genet., Suppl. to Hereditas, p. 570. 
GILES, R. 1940. Spontaneous chromosome aberration in Tradescantia. Genetics, $25,69-87$.

GILES, R. I94I. Spontaneous chromosome aberration in triploid Tradescantia hybrid. Genetics, 26, 632-649.

goldschmidt, R. 1932. Prae- oder Postreduktion der Chromosomen? Die Lösung eines alten Problems. Naturwis., 20, 358-362.

GRAY, L. H. 1952. Characteristics of chromosome breakage by different agents. Heredity, 6, Suppl., 3 1 1-315.

HAGA, T., AND KURABAYASHI, M. 1953. Genom and polyploidy in the genus Trillium. IV. Genom analysis by means of differential reaction of chromosome segments to low temperature. Cytologia, 18, 13-28.

HAGA, T., AND KURABAYASH, M. 1954. V. Chromosomal variation in natural populations of Trillium kamtschaticum Pall. Mem. Faculty of Science Kyushu Univ., Ser. E., $I$, I $59-183$.

haIR, J. в. 1952. The origin of new chromosomes in Agropyron. Heredity, 6, Suppl., $215-233$.

HARLAND, s. c. 1937. The genetics of cotton. XVII. Increased mutability of a gene in $G$. purpurascens as a consequence of hybridisation with $G$. hirsutum. 7. Genet., 34, $153-168$.

HEARNE, E. M., AND HUSKINS, C. L. 1935. Chromosome pairing in Melanoplus femur-rubrum. Cytologia, 6, 123-147.

heAtley, м. 1916. A study of the life history of Trillium cernuum. Bot. Gaz., 6I, 425-429.

HUSkiNs, C. L., AND SMITH, s. G. 1935. Meiotic chromosome structure in Trillium erectum L. Amer. J. Bot., 49, 1 19-150.

HUSKINS, c. L., AND SMTTh, s. G. 1938. Probable causes of the changes in direction of the major spiral in Trillium erectum L. Ann. Bot., N.S., 2, 281-292.

HUSKINS, C. L., AND SPIER, J. D. I934. The segregation of heteromorphic homologous chromosomes in pollen mother-cells of Triticum vulgare. Cytologia, 5, 269-277.

hUSTED, L. 1937. Chromosome breakage and knot formation in Paris and Pancratium. J. Genet., 34, 329-338.

Jefrrey, E. C., AND haerth, E. J. I939. Apomixis in Trillium. Cellule, 48, 79-88.

JONES, D. F. 1936. Segregation of colour and growth-regulating genes in somatic tissue of maize. P.N.A.S., 22, 163-166.

JoNES, D. F. $\quad$ 1936. Mutation rate in somatic cells of maize. P.N.A.S., 22, $645-648$.

KOLLER, P. C., AND DARLINGTON, C. D. 1934. The genetical and mechanical properties of the sex chromosomes. I. Rattus norvegicus ruale. 7. Genet., 29, I $59^{-1} 73$.

KURABAYASHI, M. 1952a. Differential reactivity of the specific chromosome segments in Paris. 7. Fac. of Science, Hokkaido Univ., Ser. 5, 6, 199-209.

KURABayashi, м. 1952b. Differential reactivity of chromosomes in Trillium. $\mathcal{F}$. Fac. of Science, Hokkaido Univ., Ser. 5, 6, 233-248.

KURABAyAShI, м. I954. Denaturation of chromatin and its related phenomena observed in somatic tissues under low temperature. Fap. F. Bot., I4, 349-364.

LA COUR, L. F. 195I. Heterochromatin and the organisation of nucleoli in plants. Heredity, 5, 37-50.

LA COUR, L. F. 1952. The physiology of chromosome breakage and reunion in Hyacinthus. Heredity, 6, Suppl., 163-1 79 .

LA COUR, L. F. 1954. Smear and squash techniques in plant cytology. Laboratory Practice, 3, 326-330.

LA COUR, L. F., AND RUTISHAUSER, A. I954. X-ray breakage experiments with endosperm. I. Sub-chromatid breakage. Chromosoma, 6, 696-709.

мсcLINTоск, в. 1939. The behaviour in successive nuclear divisions of a chromosome broken at meiosis. P.N.A.S., 25, 405-416.

MCCLINTOCK, B. 1941. The stability of broken ends of chromosomes in Zea mays. Genetics, 26, 234-282. 
MCCLINTOCK, в. 1942a. The fusion of broken ends of chromosomes following nuclear fusion. P.N.A.S., $28,45^{8-463}$.

MCCLINTOCK, B. 1942 $b$. The behaviour of " unsaturated " broken ends of chromosomes. T. B. Carn. Inst. Wash., 4I, 181-1 83 .

MCLeISH, J. 1952. The action of maleic hydrazide in Vicia. Heredity, 6, Suppl., 125-147.

MaheshwaRI, P. 1947. Tetranucleate embryo sacs in Angiosperms. Lloydia, io, I-1 8 .

MATHER, K. 1935. Reductional and equational separation of the chromosomes in bivalents and multivalents. 7. Genet., 30, 53-78.

MATHER, K. 1938. Crossing-over. Biological Rev., 13, 252-292.

matsuUra, H. 1937. Chromosome studies in Trillium kamtschaticum Pall. Cytologia, $8,142-177$.

MAtThey, R. 1936. La formule chromosomiale et les héterochromosomes chez les Apodemus europeeus. Z. Zellforsch., 25, 501-515.

matrhey, R. 1952. Chromosomes de Muridae (Microtinae et Gricetinae). Chromosoma, $5,113^{-1} 3^{8}$.

мüNTZING, A. 1943. Genetical effects of duplicated fragment chromosomes in rye. Hereditas, 19, 91-1 10.

RANDOLPH, L. F. I94I. Genetic characteristics of the B-chromosomes in maize. Genetics, $26,608-631$.

ReSEnde, F. 1945. Hétérochromatine. Port. Acta Biol., $I$, I 39-1 56.

REVELL, S. H. 1952. Chromosome breakage by X-rays and radiomimetic substances in Vicia. Heredity, 6, Suppl., 107-124.

RHOADES, M. 1936. The effect of varying gene dosage on aleurone colour in maize. 7. Genet., 33, 347-357.

RHOADES, M. 1938. Effect of the $D_{t}$ gene on the mutability of the $A_{1}$ allele in maize. Genetics, 23, 377-397.

RUTISHAUSER, A. 1953. Die Entwicklungserregung des Endosperms bei pseudogamen Ranunculusarten. Mitt. Nat. Ges. Schaffhausen, 25, I-45.

RUTishauser, A. 1955a. Das Verhalten der Chromosomen in arteigener und artfremder Umgebung. Viertelj. Nat. Ges. Zürich, c. (1955), 17-26.

RUTISHAUSER, A. 1955b. Genetics of endosperm. Nature, $176,210$.

RUTishauser, A. 1956. Genetics of fragment chromosomes in Trillium grandiflorum. Heredity, 1o, 195-204.

RUTISHAUSER, A., AND HUNZIKER, H. R. 1950. Untersuchungen über die Cytologie des Endosperms. Arch. 7. Klaus-Stiftung f. Vererb.-forschg., 25, 477-483.

RUTISHAUSER, A., AND LA COUR, L. F. 1956. Spontaneous chromosome breakage in endosperm. Nature, ${ }^{777}, 324-325$.

RUTISHAUSER, A., AND LA COUR, L. F. I956. Spontaneous chromosome breakage in hybrid endosperms. Chromosoma, 8, 31 7-340.

SPANGler, R. C. I925. Female gametophyte of Trillium sessile. Bot. Gaz., 79, $217-221$.

SPARROW, RH. C., AND SPARROW, A. H. 1950. Spontaneous chromosome fragmentation in Trillium erectum. Americ. Nat., $84,477-488$.

SWAMY, B. G. L. 1948. On the post-fertilization development of Trillium undulatum. Cellule, 52, 1-14.

VANDERLYN, L. 1949. The heterochromatin problem in cyto-genetics as related to other branches of investigation. Bot. Rev., 15, 507-582.

WENRICH, D. H. 1916. The spermatogenesis of Phrynotettix magnus, with special reference to synapsis and the individuality of the chromosomes. Bull. Mus. Comp. Zool. Harv., 6o, 57-135.

WILSON, G. B., AND BOOTHROYD, E. R. I94I. Studies in differential reactivity. I. The rate and degree of differentiation in somatic chromosomes in Trillium erectum L. Canad. 7. Res., 19, 400-412. 